\title{
Estimating the Return to Training and Occupational Experience: The Case of Female Immigrants *
}

\author{
Sarit Cohen-Goldner \\ Bar-Ilan University (cohens1@mail.biu.ac.il) \\ Zvi Eckstein \\ Tel Aviv University, The University of Minnesota \\ and The Federal Reserve Bank of Minneapolis (eckstein@post.tau.ac.il)
}

July 21, 2004

\footnotetext{
${ }^{*}$ We received valuable comments from Chemi Gotlibovski, Bob LaLond and Yoram Weiss. Financial support from the Israeli Science Foundation grant \#884/01 is greatly appreciated.
} 


\begin{abstract}
Do government provided training programs benefit the participants and the society? We address this question in the context of female immigrants who first learn the new language and then choose between working or attending government provided training. Although theoretically training may have several outcomes, most evaluations have focused on only one outcome of training: the expected wage. However, training might have no direct effect on wage, but, nevertheless, affect employment probability in higher paid jobs. In order to measure the return to government provided training, and overcome the above reservations, we formulate an estimable stochastic dynamic discrete choice model of training and employment. Given the estimated model, the individual benefit is measured by the change in expected life time utility due to the effect of alternative training policy. The social return from training is measured by the expected increase in actual earnings minus the cost, due to a couterfactual policy.

Our estimates imply that training has no significant impact on the mean offered wage in bluecollar occupation, but training increases the mean offered wage in white-collar occupation by 19 percent. Training also substantially increases the job offer rates in both occupations. Furthermore, counterfactual policy simulations show that free access to training programs relative to no training could cause an annual earnings growth of 31.3 percent. This large social gain (ignoring the cost of the program) comes mainly from the impact of training on the job offer probabilities and, consequently, on unemployment, and not, as conventionally thought, from the impact of training on potential earnings. Moreover, the average ex-ante expected present value of utility for a female immigrant at arrival (individual benefit) increases by 50 percent using a counterfactual policy of fully available training relative to the estimated restricted level of training opportunity.
\end{abstract}

JEL classification: J310, J680

Keywords: Immigration, occupation, training, transitions, unemployment, welfare. 


\section{Introduction}

Do government provided training programs benefit the participants and the society? Heckman, LaLonde and Smith (1999) answer that: "As currently constituted, these programs are often ineffective on both counts". We address this question in the context of female immigrants who first learn the new language (Hebrew) and then choose between working or attending government provided training, where the availability of both options is uncertain. Conditional on participation in training, the female decides whether to accept a white-collar or a blue-collar job if one or both are offered. The job offer rate and the associated wage depend on the occupation and the participation in training program. Within this reality, we measure the female immigrant benefit and the social return to the existence of government training programs. ${ }^{1}$

The individual benefit from the availability of training is measured in this study by the increase in expected lifetime utility, which consists of the effect of training on employment, wages and preferences. The social return from training is measured here, as in all studies, by the expected increase in actual accepted wages minus the cost of the program. ${ }^{2}$ Although training may have several outcomes, most evaluations have focused on only one outcome of training: the expected wage. $^{3}$ However, suppose training has no direct impact on wages and that the distribution of offered wage in occupation $j$ first-order stochastically dominants the distribution of offered wage in occupation $i$. If training increases the propensity to be employed in occupation $j$, then we may observe a wage increase due to training. Ignoring the impact of training on occupational choice and using the standard before-after estimator may, therefore, lead to specious inference that training has a positive impact on the mean wage.

In order to measure the return to government provided training, and overcome the above reservations, we formulate an estimable stochastic dynamic discrete choice model of training and employment. The model constructs dynamically selection rules that are consistent with optimal dynamic

\footnotetext{
${ }^{1}$ We consider here government sponsered vocational classroom training $(\mathrm{CT})$ programs.

${ }^{2}$ The assumption is that the increase in output is equal to the increase in accepted wages due to the training program. This calculation takes into account the effect of training both on wages and employment.

${ }^{3}$ Heckman, LaLonde and Smith (1999) report the result from the litrature that estimate the individual and the social benefit of training by either the estimated effect on mean wage or employment (unemployment) probability Despite the different approaches taken in various studies, numerous experimental and non-experimental evaluations in OECD countries lead to the same conclusion that the return to training (measured by increase in wage) is approximately zero. However, training programs in Europe usually have a significant effect on employment rates. Todd and Wolpin (2003) used a dynamic structural model to evaluate the benefits and costs of a large social policy program in Mexico that aims at increasing schooling attendence by children.
} 
choices of the individual. Specifically, each female immigrant sequentially chooses among working in a white-collar or a blue-collar job, attending a training program and not working, in order to maximize her discounted expected utility. Both the availability of job offers, the training program and the wage offers are random. The investment in local human capital is in the form of participating in training (but not working), and in the accumulation of occupation-specific local work experience. These investments affect the mean offered wages and the probability of these occupation-specific job offers. The estimated benefits depend on both the estimated parameters of the model and the individual predicted decisions conditional on these parameters. ${ }^{4}$

In estimating the effect of training on the mean wage, the dynamic programing (DP) model provides a conditional probability for both the selection to the training program and the selection of jobs after the training programs. ${ }^{5}$ Furthermore, these estimated conditional probabilities directly determine the predicted individual and social benefits from the training programs. The main contribution of this paper is in formulating and estimating the individual and social benefits to local accumulated human capital for a sample of female immigrants. ${ }^{6}$ This measurement application is based on internally consistent theory that is estimated using actual labor market data of female immigrants who are followed quarterly for five years since arrival to Israel. The estimated model provides a good fit for the aggregate division of the female labor force between the two occupations, training and unemployment, for the five years since arrival. Hence, other estimable models for the same data are, at best, observationally equivalent.

The estimates of the wage function imply that training has no significant impact on mean offered wage in blue-collar (BC) occupation, but training increases the mean offered wage in whitecollar (WC) occupation by 19 percent. Training substantially increases the job offer rates in both occupations. The probability of an unemployed immigrant with no work experience to receive a WC

\footnotetext{
${ }^{4}$ The model is similar to that of Cohen and Eckstein (2002) that follow the formulations of Keane and Wolpin (1997) and Eckstein and Wolpin (1999). Heckman, LaLonde and Smith (1999) proposed a stationary continuous time search model to analyze the duration and the choice of training programs. They used the model to rationalize results from reduced form regressions for employment and training duration outcomes (e.g., Card and Sullivan, 1988), but they did not formulate the model to be directly estimated.

${ }^{5}$ The DP model provides the selection probability for all events related to training: the choice of the worker to attend training; the choice of the provider to accept the worker; the job offer rate a following the training and the job acceptance decision of the worker. The existing literature (see Heckman, LaLonde and Smith, 1999 , and Manski, 1995) studied only the first two choices.

${ }^{6}$ The sample is of 502 female immigrants who came in the initial wave (1989-1992). Following these immigratns for at most twenty quarters provides us with 7205 observations on labor states outcomes. These immigrants have an average of 14.5 years of schooling. The average unemployment rate among these immigrants during their first year in Israel was over $50 \%$ and it dropped considerably with tenure in Israel. About $43 \%$ of the immigrants in our sample participated in a CT program, where most of them have done so during the first year in Israel.
} 
(BC) job offer in the subsequent quarter after training is 5.6 (3.4) times higher than the probability of an immigrant who has not attended training. Furthermore, the effect of training on WC job offer probabilities, in later quarters, varies between 179 percent, for an unemployed immigrant with no WC experience, to 38 percent for a female immigrant who has accumulated 20 quarters of WC experience. ${ }^{7}$

The estimated model includes a parameter for the availability rate of the government provided training program. We find that every quarter the training program was available with $0.14(0.06)$ probability for a female immigrant that was younger (older) than 40 at arrival. We compare the outcomes for the female immigrant in this estimated economy ("benchmark economy") to two counterfactual policy experiments. Policy A where no training is available, and, policy B, where training is always available (i.e, offer rate for training is one). We find that the annual mean earnings for the sample under policy A, decreases by 18.2 percent relative to the benchmark economy, while policy B causes the annual mean earnings to increase by 13.1 percent relative to the benchmark economy. Hence, training programs could cause an annual wage growth of 31.3 percent, which is the gross social value of the training programs for female immigrants. Furthermore, we find that most of this gain is due to the increase in job offer rate for white-collar occupations and, consequently, the reduction of unemployment and almost none of this gain is due to the direct impact of training on the wages. ${ }^{8}$

For the benchmark economy (limited training) the model predicts that about 50 percent of females would participate in training, but if training is always available (policy experiment B), about 80 percent of the females would participate in training. ${ }^{9}$ Moreover, under this training policy the average expected present value of female immigrant increased by 50 percent, but if no training is available (policy experiment A), it would decrease by 41 percent. These results suggest that the main impact of training is in integrating unemployed in the labor market and blue-collar immigrants in high paying jobs through the change in job offer arrival rates.

We find that the distinction between white-collar and blue-collar specific work experience plays

\footnotetext{
${ }^{7}$ These findings are fully consistent with the existing literature (Heckman, LaLonde and Smith, 1999). That is, the effect of training on the mean wage offer for less advantage workers is close to zero. However, training significantly affect the employment probability (Ham and LaLond, 1996). Furthermore, these findings are qualitatively and quantitatively similar to those we find for male immigrants in Cohen and Eckstein (2002).

${ }^{8}$ In order to complete the cost-benefit analysis of the training programs on need to compute the costs for each case. This technical part is avoided here since we do not see the paper directed for actual policy design.

${ }^{9}$ The actual number of participants in training is 218 . The Benchmark economy refers to the prediction based on the estimated model, assuming that all the 502 females are followed for 20 quarters.
} 
a major role in the wage growth and the occupational choice. Accumulation of blue-collar workexperience market does not contribute to the wage growth in the two occupations and does not affect the probability of receiving blue-collar job-offers. On the other hand, an additional quarter of white-collar experience increases the probability of receiving a white-collar job-offer by about nine to twenty percent, and white-collar experience increases the wage in white-collar jobs by four percent. These estimates imply that wages of immigrants in relatively low-skilled jobs (blue-collar) are not expected to grow substantially with the experience accumulated in these jobs. However, immigrants who have found a job in white-collar occupation are expected to gain a rapid wage growth in the short run, due to white-collar-specific work experience.

These findings emphasis the contribution of the paper for the measurement of the social and individual gain from training (investment in human capital). First, the participation decision and the mean and variance of the observed outcomes (employment and wages) are affected by the availability (offer rate) of the training and the impact of training on job offers. Second, the analysis of the social and private gain requires the joint analysis of outcomes (employment and wages). Third, the main economic costs of the investment in training (education) is the foregone accumulation of experience that provides a very high return given that schooling investment is optimal. ${ }^{10}$

The rest of the paper is organized as follows. In the next section we describe the data and show the main facts that the model should fit and that motivate the structure. In section 3 we formulate and solve an estimable model for the analysis of training and occupational choice. Section 4 includes the description of the results and section 5 provides the analysis of active labor market policies. Section 6 concludes.

\section{The Data}

The data for this study is based on a panel from two retrospective surveys of the same sample. ${ }^{11}$ The first survey was conducted during the summer of 1992 on a random sample of 1,200 male and female immigrants from the former USSR who entered Israel between October 1989 and January

\footnotetext{
${ }^{10}$ For example, Card(2001) model of education decision ignores the potential loss of experience and the potential bias that is due to this endogenous alternative choice. That is, "ability" may be correlated with high wage offers while in school, in jobs with high return on experience.

${ }^{11}$ The surveys were conducted by the JDC - Brookdale Institute of Gerontology and Human Development, Jerusalem- Israel.
} 
1992. The second survey was done in 1995 and only 901 of these immigrants were re-sampled. The original sample consists of immigrants between working-ages (25-65) residing in 31 different locations in Israel at the time of the first survey. Both surveys contain monthly history of the jobs and wages from the date of arrival in Israel until the interview. The surveys also provide detailed information on participation in government-sponsored training programs, the knowledge of Hebrew on arrival, participation in Hebrew classes and Hebrew knowledge at the date of the surveys. For this study, we converted the monthly labor market data to a quarterly (three months) data set.

We use the two surveys to construct a panel of 502 female immigrants who were 25-55 years old at arrival and who have actively searched for a job in Israel since their arrival. ${ }^{12}$ We follow these immigrants for, at most, their first 20 quarters in Israel and build their jobs-profile from arrival until the last interview. For each job, we have information on the starting and ending dates, occupation, weekly hours and wage. There are 7205 observations on labor market states and 649 wage observations. ${ }^{13}$ An important feature of our data set is information on actual work experience accumulated in Israel in various occupations, which is essential for the study of female life cycle labor supply.

The surveys also contain detailed information on immigrants' participation in governmentsponsored vocational classroom training (CT) and their participation in Hebrew classes ("Ulpan" in Hebrew). The immigrants also provided background information as the occupation held in the former Soviet-Union, years of schooling, Hebrew knowledge before migration and place of residency in the former Soviet-Union. Table 1 presents the sample means for the full sample and by participation in training.

As Table 1 indicates, $43 \%$ (218) of the women in the sample have participated in a CT program since their arrival. These programs were offered by The Ministry of Labor and The Ministry of Absorption as a part of an 'Absorption package' each immigrant was entitled to upon arrival in Israel. The training programs include courses in sales, cosmetics, diamond cutting, computers etc. The average length of these programs is six months and the average weekly hours is $25.6{ }^{14}$ Despite the long duration of the Israeli training programs, less than $5 \%$ of the participants dropped out from training. ${ }^{15}$ The low dropout rate might be due to the importance the immigrants attribute

\footnotetext{
${ }^{12}$ We excluded 13 women whose work pattern is inconsistent with the model assumptions.

${ }^{13}$ In the first survey of 1992 , the immigrants were asked only about the wage in the last job they reported.

${ }^{14}$ For comparison, in the UK and the US, classroom training typically lasts about 3 months.

${ }^{15}$ In some experiments in the US dropout can reach $40 \%$ of the treatment group (Heckman, Smith and Lalonde
} 
to training, or due to the lack of alternative activities the immigrants can engage in. According to Table 1 the trainees are, on the average, younger on arrival and have more years of schooling.

Table 1: Summary Statistics

\begin{tabular}{|c|c|c|c|}
\hline Variable & Full sample & Not Trained & Trained \\
\hline Number of observations & 502 & 284 & 218 \\
\hline Age at arrival & $\begin{array}{l}37.2 \\
(8.5)\end{array}$ & $\begin{array}{l}38.9 \\
(8.9)\end{array}$ & $\begin{array}{l}35.0 \\
(74)\end{array}$ \\
\hline Years of schooling & $\begin{array}{l}14.5 \\
(2.4)\end{array}$ & $\begin{array}{l}13.9 \\
(2.5)\end{array}$ & $\begin{array}{l}15.2 \\
(2.0)\end{array}$ \\
\hline Number of children & 1.05 & 1.01 & $\begin{array}{l}1.1 \\
(0.8)\end{array}$ \\
\hline Number of jobs since arrival & $\begin{array}{l}1.8 \\
(1.0)\end{array}$ & $\begin{array}{l}1.6 \\
(0.9)\end{array}$ & $\underset{(1.0)}{2.0}$ \\
\hline Time in Israel (months) & $\begin{array}{l}43.2 \\
(14.0)\end{array}$ & $\begin{array}{l}40.5 \\
(15.6)\end{array}$ & $\begin{array}{l}46.7 \\
(10.9)\end{array}$ \\
\hline Unemployed $*(\%)$ & 15.1 & 21.1 & 7.3 \\
\hline Had Hebrew knowledge before migration(\%) & 15.7 & 12.0 & 20.6 \\
\hline Worked in white-collar job before migration(\%) & 75.7 & 69.3 & 83.9 \\
\hline Married(\%) & 76.5 & 77.1 & 75.7 \\
\hline Hebrew fluency index-first survey & $\begin{array}{l}2.99 \\
(0.77)\end{array}$ & 2.71 & $\begin{array}{l}3.00 \\
(0.83)\end{array}$ \\
\hline Hebrew fluency index-second survey & $\begin{array}{l}3.30 \\
(0.75) \\
\end{array}$ & $\begin{array}{r}3.36 \\
(0.62) \\
\end{array}$ & $\begin{array}{r}3.62 \\
(0.48) \\
\end{array}$ \\
\hline
\end{tabular}

Source: Brookdale employment surveys. Standard Deviation in parenthesis.

* Percentage of immigrants who have been permanently unemployed since their arrival and actively searched for a job.

We divide the various occupations into two groups: academic, managerial, technical and other white-collar occupations, ${ }^{16}$ which is referred to as white-collar (WC) occupation, and all other occupations, which are referred to as blue-collar (BC) occupation. About $97 \%$ of the women in our sample worked in the former Soviet-Union, and $76 \%$ worked in WC occupations while only $21 \%$ in $\mathrm{BC}$ occupations. Of those who had worked in WC occupation before migration, almost half attended training, compared to $24 \%$ of those who had worked in $\mathrm{BC}$ occupation in the former Soviet-Union. The Hebrew index variable is based on four questions that were asked in the two surveys about the immigrant's ability to use the local language. This index ranges between 1 (no knowledge) to four (full control in Hebrew). Trainees know Hebrew more than non trainees for reasons discussed below.

\section{Labor Market States}

\section{(1999).}

${ }^{16}$ Codes 000-299 in the 1972 occupation classification of the Israel Central Bureau of Statistics (CBS). 
Figure 1 presents the aggregate proportion of immigrants' employment in $\mathrm{WC}$ and $\mathrm{BC}$ occupations, unemployment and participation in training over time. The share of the employed increased sharply during the first two years in Israel and continued to increase subsequently at a moderate rate. One year (4 quarters) after migration, $37 \%(=0.069+0.299)$ of the women were employed, $46 \%$ were unemployed and $17 \%$ attended training. After four years in Israel, $82 \%$ of the immigrants were employed while $16 \%$ were unemployed and only $2 \%$ attended training. Training attendance increases after arrival, peaks after one year of residency in Israel, and slowly declines in later periods. A substantial share of immigrants work in $\mathrm{BC}$ jobs which reaches more than 56 percent after four years in Israel. What might seem as a substantial occupational downgrading during the first 4 years in the new country, gets a significant turn later on. During the fifth year in Israel, the share of immigrants who work in BC jobs is reduced by $16 \%$ and the share of employed in white-collar jobs increases by almost the same magnitude. Hence, the movement between-replace with mobility across occupations is a long dynamic process. ${ }^{17}$ Is this change in trend evidence for occupational upgrading during the fifth year since migration, or is it a result of the characteristics of the 1989/1990 immigrants, which we observe for five years, relative to the 1991/2 immigrants, which we observe for four years? The answer to this question requires an estimable model which is capable of distinguishing between these two alternative explanations. We provide the answer using the model.

\section{Training}

Table 2 presents the distribution of the number of jobs the immigrant had held in Israel prior to her participation in training. The Table shows that about $60 \%$ (i.e. $52.75+7.34$ ) of the trainees participated in training before they have ever worked in Israel. This pattern is consistent with predictions of human capital theory, where individuals choose to invest in human capital early in their life-cycle and enjoy the return for a longer time. However, the causality is not clear. It might be the case that those immigrants who failed to find a job, 'were forced' to attend training in order to improve their employment opportunities.

\footnotetext{
${ }^{17}$ It should be noted that this pattern of switch at the fifth year exists also for men. Moreover, the general pattern of labor market activities over the first five years in Israel for females is similar to that of males (see Cohen and Eckstein, 2002), but the levels are different.
} 
Table 2: Distribution of Number of Jobs Prior to Participation in Training

\begin{tabular}{c|cc}
\hline \hline $\begin{array}{c}\text { Jobs prior to } \\
\text { participation in training }\end{array}$ & Number of Observations & \\
\hline 0 & 115 & 52.75 \\
1 & 63 & 28.90 \\
2 & 18 & 8.26 \\
3 & 4 & 1.83 \\
4 & 2 & 0.92 \\
$99^{*}$ & 16 & 7.34 \\
\hline Total & 218 & 100.00 \\
\hline \hline
\end{tabular}

Source: Brookdale employment surveys.

* Women who have never worked in Israel since their arrival, but have actively searched for a job.

Figure 2 plots the actual hazard rate to training as a percentage of non-trained in each quarter. The hazard peaks after three quarters and decreases subsequently, though not monotonically. Immigrants are required to have knowledge of Hebrew before they enroll in a training program. Most of the immigrants (84\%) had no Hebrew knowledge upon arrival, and, therefore, $94 \%$ of the immigrants attended Hebrew school (Ulpan) during their first 4-6 months in Israel. After two quarters all the immigrants were eligible to participate in training programs and most of those who went to training entered the program during the third quarter in Israel. Since the eligibility of immigrants to participate in government sponsored training is denied after few years, we observe increasing hazard to training after three years of residency in Israel.

Table 3 presents data moments, using the logit regression, on the probability to attend training conditional on observed state characteristics at arrival. These estimates show that years of education and previous experience in white-collar work in before immigration are positively correlated with the participation in training. Thus, immigrants with higher human capital at arrival are more likely to invest in the host country human capital by participating in training. As expected, the probability to participate in training decreases with age at arrival, with being married and with their number of children. 
Table 3: Logit Results for Participation in Training

\begin{tabular}{l|r}
\hline \hline Variable & Estimate \\
\hline Constant & -1.3701 \\
& $(0.8106)$ \\
Age at arrival & -0.0762 \\
& $(0.0135)$ \\
Married & -0.0946 \\
& $(0.2375)$ \\
Number of children & -0.0611 \\
& $(0.1314)$ \\
WC occupation in former Soviet-Union & 0.5199 \\
Years of schooling & $0.2657)$ \\
& 0.2500 \\
Number of observations & 502 \\
Pseudo $R^{2}$ & 0.1101 \\
Log likelihood & -305.76 \\
\hline \hline
\end{tabular}

Source: Brookdale employment surveys

S.E. in parenthesis

\section{Transitions}

Table 4 presents the total number and proportion of quarter-to-quarter transitions between the four labor market states. There is a high level of state dependence in occupation-specific employment, as $95.6 \%$ (92.9\%) of the immigrants who worked in a WC (BC) occupation, continue to work in the same occupation in the subsequent quarter. ${ }^{18}$ Transitions from one occupation to the other are rare. However, some transitions may occur indirectly through training and unemployment. Direct transitions from training to $\mathrm{WC}$ and $\mathrm{BC}$ are considerably higher than the transitions from unemployment to the two employment states, indicating potential employment gain from training.

Table 4: Number and Proportions of Actual Quarterly Transitions

\begin{tabular}{|c|c|c|c|c|c|c|c|c|c|}
\hline To & \multicolumn{2}{|c|}{ White-Collar } & \multicolumn{2}{|c|}{ Blue-Collar } & \multicolumn{2}{|c|}{ Training } & \multicolumn{2}{|c|}{ Unemployment } & Total \\
\hline White-Collar & 918 & $(95.6 \%)$ & 7 & $(0.7 \%)$ & 12 & $(1.3 \%)$ & 23 & $(2.4 \%)$ & 960 \\
\hline Blue-Collar & 14 & $(0.5 \%)$ & 2414 & $(92.9 \%)$ & 51 & $(2.0 \%)$ & 120 & $(4.6 \%)$ & 2599 \\
\hline Training & 33 & $(7.6 \%)$ & 71 & $(16.5 \%)$ & 222 & $(51.5 \%)$ & 105 & $(24.4 \%)$ & 431 \\
\hline Unemployment & 101 & $(3.7 \%)$ & 330 & $(12.2 \%)$ & 154 & $(5.7 \%)$ & 2128 & $(78.4 \%)$ & 2713 \\
\hline Total & 1066 & & 2822 & & 439 & & 2376 & & 6703 \\
\hline
\end{tabular}

Source: Brookdale employment surveys

Row percentage in parenthesis.

\footnotetext{
${ }^{18}$ Transition form training to training implies that the immigrant participated in a program that lasted more than one quarter.
} 


\section{Wages}

In the 1992 survey the immigrant was asked about the last wage she received and in the 1995 survey she was asked about the wage in each job she reported in the second survey, such that there are total of 649 wage observations. The mean wage in WC (BC) occupation is 12.5 (11.6) NIS per hour during the first year in Israel. During the fifth year of residency in Israel the mean wage in WC (BC) occupation is 22.1(10.8) NIS per hour. ${ }^{19}$ It is the case that the mean wage in WC jobs increases over time, whereas the mean wage in $\mathrm{BC}$ jobs is roughly constant . Furthermore, wages in white-collar jobs are more volatile than in blue-collar jobs.

Standard OLS of log hourly wage regressions with robust standard errors are presented in Table $5 .{ }^{20}$ As can be seen there is no impact of imported human capital in the form of schooling and experience (age at arrival) from the Former Soviet Union on wage in Israel. Almost all the variables in the two wage regressions for $\mathrm{WC}$ and $\mathrm{BC}$ are insignificant. The return to training in $\mathrm{WC}$ occupation is very large (16\%) and significant at $10 \%$ level.

Table 5: OLS Wage Regression

\begin{tabular}{l|c|c}
\hline \hline \multicolumn{1}{c|}{ Variable } & $\begin{array}{c}\text { Wage in WC } \\
\text { Occupation }\end{array}$ & $\begin{array}{c}\text { Wage in BC } \\
\text { Occupation }\end{array}$ \\
\hline Constant & $1.7614^{a}$ & $1.8351^{a}$ \\
Schooling & $(0.7145)$ & $(0.1634)$ \\
& 0.0218 & -0.0004 \\
Age at arrival & $(0.0264)$ & $(0.0086)$ \\
WC experience & 0.0057 & 0.0024 \\
& $(0.0065)$ & $0.0024)$ \\
BC experience & $0.0372^{a}$ & 0.0269 \\
Hebrew & $(0.0122)$ & $(0.0226)$ \\
Training & 0.0006 & 0.0045 \\
& $(0.0198)$ & $0.0045)$ \\
Number of Observations & 0.0621 & 0.0943 \\
$R^{2}$ & $(0.1416)$ & $-0.0432)$ \\
\hline \hline
\end{tabular}

Source: Brookdale employment surveys.

S.E. in parenthesis. $a$ significant at $5 \%$ level. $b$ significant at $10 \%$ level.

\footnotetext{
${ }^{19}$ All wages are in July 1995 prices.

${ }^{20}$ Obviously, these regressions do not correct for the selection biases due to the immigrant's self selection to work, training and occupations. Note that the indicator for training equals 1 only if the wage was reported after the graduation of the training program.
} 


\section{The Estimable Model}

In this section we formulate a finite-horizon dynamic discrete choice model for the integrated labor supply and human capital investment decisions of female immigrants. The model follows the dynamic programing models of labor supply and schooling (Keane and Wolpin (1997) and Eckstein and Wolpin(1999)), where an individual sequentially chooses among a finite set of mutually exclusive alternatives over a finite horizon, in order to maximize her discounted expected utility. The model incorporates observed heterogeneity, such as, marital status, number of children, years of schooling, age at arrival etc., as well as unobserved heterogeneity (Heckman and Singer (1984)).

Each immigrant at each period $t$, starting at arrival in Israel and ending at retirement, chooses an element $a$ among her choice set $A$, which contains four alternatives: employment in white-collar (WC) occupation $(a=1)$, employment in blue-collar $(\mathrm{BC})$ occupation $(a=2)$, participation in training $(a=3)$ and unemployment $(a=4){ }^{21}$ The choice variable, $d_{a t}$, equals 1 if the $a$ element was chosen in period $t$ and equals zero otherwise. ${ }^{22}$ The four alternatives are mutually exclusive, implying $\sum_{a=1}^{4} d_{a t}=1$ for every $t$. The periodic utility of a female immigrant, $U_{t}$, is assumed to be linear and additive in consumption and labor market state, such that,

$$
\begin{aligned}
U_{t}= & \left(\gamma_{1 m} M+\gamma_{1 c} N\right)\left(d_{1 t}+d_{2 t}\right) \\
& +\left(\gamma_{2 m} M+\gamma_{2 c} N+\gamma_{3 l}+\varepsilon_{3 t}\right) d_{3 t} \\
& +\left(\gamma_{3 m} M+\gamma_{3 c} N+\gamma_{4 l}+\varepsilon_{4 t}\right) d_{4 t} \\
& +C_{t}
\end{aligned}
$$

where $M$ is an indicator equals 1 if the immigrant is married, $N$ is the number of children, both are assumed to be exogenous, and $C_{t}$ is the consumption of a composite good in period $t .^{23}$ The utility from children, marriage and leisure depends on employment, attending training or being unemployed.

\footnotetext{
${ }^{21} \mathrm{WC}$ and $\mathrm{BC}$ occupations are also referred to as occupation 1 and 2, respectively.

${ }^{22}$ For notation simplicity, we omit the individual index in this section.

${ }^{23}$ Studies that modeled female life-cycle marital status and labor supply decisions (Van der Klaauw (1996)), or life-cycle fertility and labor supply decisions (Hotz and Miller (1988), Eckstein and Wolpin(1989)), treated female's labor supply as a binary decision (i.e. the women either works or not). In this paper we focus on different labor market activities the woman can engage in (i.e. not only does she work, but also in what occupation does she work etc.). Therefore, we do not incorporate the marriage and fertility decisions into our model.
} 
The female budget constraint at each period $t, t=1, . ., T$ is given by,

$$
d_{1 t} w_{1 t}+d_{2 t} w_{2 t}+d_{3 t} T W+d_{4 t} U B+A I_{t}=C_{t}+g_{1} N \cdot\left(d_{1 t}+d_{2 t}\right)+g_{2} N \cdot d_{3 t}+g_{3} N \cdot d_{4 t}
$$

where $w_{a t}$ is the immigrant's wage in WC occupation $(a=1)$ or in $\mathrm{BC}$ occupation $(a=2) . T W$ is the subsidy the immigrant receives while attending training $(a=3)$ and $U B$ is the unemployment benefit. $A I_{t}$ represents additional sources of income that do not depend on the immigrant's choice, such as the earnings of the husband. The cost of children is denoted by $g_{a} N$, and it may differ if the immigrant works $(a=1,2)$, participates in training $(a=3)$ or is unemployed $(a=4)$. Given the linearity of preferences we can write the periodic utility, $U_{t}$, as

$$
U_{t}=\sum_{a=1}^{4} U_{a t} d_{a t}
$$

where $U_{a t}$ is the periodic utility associated with choosing alternative $a$ at time $t$. Substituting $C_{t}$ obtained from (2) in (1), the alternative state specific utilities at time $t$ are:

$$
\begin{aligned}
U_{1 t} & =w_{1 t}-g_{1} N+\gamma_{1 m} M+\gamma_{1 c} N+\gamma_{1 l} \\
U_{2 t} & =w_{2 t}-g_{1} N+\gamma_{1 m} M+\gamma_{1 c} N+\gamma_{2 l} \\
U_{3 t} & =T W-g_{2} N+\gamma_{2 m} M+\gamma_{2 c} N+\gamma_{3 l}+\varepsilon_{3 t} \\
U_{4 t} & =U B-g_{3} N+\gamma_{3 m} M+\gamma_{3 c} N+\gamma_{4 l}+\varepsilon_{4 t}
\end{aligned}
$$

where $\varepsilon_{3 t}$ and $\varepsilon_{4 t}$ are the time varying utility shocks which are assumed to be serially uncorrelated. Note that under the assumption that the utility is additive and separable in consumption, the additional sources of income in (2), $A I_{t}$, are neutral across the four alternative and do not affect immigrants' choices. ${ }^{24}$

The stochastic offered wage in occupation $j, w_{j t},(j=1,2)$ follows a standard Mincerian wage

\footnotetext{
${ }^{24}$ No data on husband's wage and employment status (i.e. employed, unemployed) is available from the Brookdale surveys. The assumption that the husband always works is too strong for immigrants who have just arrived in a new country and enter a new labor market. In order to account for potential impact of husband's wage on the wife's decisions, additional assumptions about the predicted patterns of the husband's wage and employment have to be made (for example, see Eckstein and Wolpin (1989), Baker and Benjamin (1997) and Duleep, et al. (1999)).
} 
function with cross-experience terms:

$$
\begin{aligned}
w_{j t}= & \exp \left(\alpha_{0 j}+\alpha_{1 j} S C+\alpha_{2 j} k_{1 t-1}+\alpha_{3 j} k_{1 t-1}^{2}+\alpha_{4 j} k_{2 t-1}+\alpha_{5 j} k_{2 t-1}^{2}+\alpha_{6 j} D T_{t}\right. \\
& \left.+\alpha_{7 j} A G E+\alpha_{8 j} H e b_{t}+\varepsilon_{j t}\right)
\end{aligned}
$$

where $S C$ denotes the immigrant's imported years of schooling. The endowment of schooling is assumed to be exogenous since the option to migrate to Israel was not feasible when the schooling decision was made. $k_{j t-1}$ is the actual work experience that the immigrant has accumulated in occupation $j$ since her arrival until period $t$ and $D T_{t}$ is an indicator that equals one if the immigrant has completed a training program before period $t$. $A G E$ represents the immigrant's age at arrival and $\mathrm{Heb}_{t}$ is the immigrant's Hebrew knowledge at time $t$. Training evaluation literature has focused on the parameter $\alpha_{6 j}$, which is known as the mean return to training. ${ }^{25} \alpha_{2 j}, a_{3 j}, \alpha_{4 j}, \alpha_{5 j}$ and $\alpha_{6 j}$ measure the contribution of different forms of human capital that the immigrant accumulates in Israel to her potential earnings. $\varepsilon_{j t}$ is a time varying occupation-specific shock, which is assumed to be serially uncorrelated. Under the last assumption, time dependence in wages is related to the immigrant's decisions via work experience accumulation and participation in training and not to randomness. The random elements $\varepsilon_{t}=\left[\varepsilon_{1 t}, \varepsilon_{2 t}, \varepsilon_{3 t}, \varepsilon_{4 t}\right]$ are assumed to be distributed joint normal and serially independent, such that, $\varepsilon_{t} \backsim i i d N(0, \Omega)$, where $\Omega$ is not restricted.

The occupation-specific work experience stocks evolve according to

$$
\begin{aligned}
& k_{1 t}=k_{1 t-1}+d_{1 t} \\
& k_{2 t}=k_{2 t-1}+d_{2 t},
\end{aligned}
$$

where the initial values of the endogenous human capital variables are given by the level of these variables at arrival in Israel, implying $k_{1,0}=k_{2,0}=D T_{0}=0$. The immigrant's choices take into account that future job opportunities and wage offers depend on the endogenously accumulated occupation-specific work experience and training status.

\footnotetext{
${ }^{25}$ The common assumption in the literature is that the return to training is independent of occupation.
} 
The objective of the immigrant is, thus, to maximize:

$$
E\left[\sum_{t=1}^{T} \beta^{t} \sum_{a=1}^{4} U_{a t} d_{a t} I_{a t} \mid S(0)\right]
$$

by choosing a sequence of the control variables $d_{a t}$ for all $t=1, \ldots ., T$, where $t$ is time since arrival, $T$ is the retirement period and $\beta$ is the discount factor. $I_{a t}$ is an indicator function that is equal to one if alternative $a$ is available at time $t .{ }^{26}$ The expectation operator $E[\bullet \mid S(0)]$ is defined over the distribution of $\varepsilon_{t}$ and the probability of availability of labor market states as it is defined below. Finally, $S(0)$ is the individual's state space at arrival $(t=0)$ which contains all the variables that are known to the immigrant at this period and affect either her current or future utility.

The availability of labor states at each date $t$ in the optimization (7) is determined as follows. The immigrant can always choose to be unemployed, such that $I_{4 t}=1$ for all $t$. In each period, the immigrant can receive job offers in occupation 1 and 2, independently. Furthermore, at each period $t$ there is an exogenous probability, $1-s_{j}$, that the worker stays at the same occupation such that $s_{j}$ is the exogenous probability that an employed immigrant be separated from her job in occupation $j, j=1,2$. An immigrant who is currently employed in occupation $j, j=1,2$ faces an exogenous separation probability from her job, $s_{j}$. The probability of receiving a job offer in occupation $j, j=1,2$ at time $t$, depends on the labor market activity that the immigrant engaged in during the previous period $\left(d_{a t-1}\right)$, as well as on the immigrant's years of schooling, age at arrival, participation in training, occupation in the former Soviet-Union (denoted by $U O C$ ) and accumulated work experience in occupation $j$. We adopt the following logistic form for the job offer probability,

$$
\begin{aligned}
\lambda_{j t}= & \frac{\exp \left(Q_{j t}\right)}{1+\exp \left(Q_{j t}\right)}, \quad \text { where } j=1,2 \\
Q_{j t}= & b_{10 j} d_{3 t-1}+b_{11 j} d_{4 t-1}+b_{12 j} d_{-j t-1}+b_{2 j} S C+b_{3 j} A G E+b_{4 j} D T_{t} \\
& +b_{5 j} U O C+b_{6 j} k_{j t-1}+b_{7 j} H e b_{t}
\end{aligned}
$$

where $d_{-j-1}=1$ if the immigrant was employed in an occupation other than $j$ at $t-1$.

The institutional design of training programs imposes restrictions on participation in training.

${ }^{26}$ Detailed institutional and other considerations imply specific values for $I_{a t}$ which are explained below. 
Each immigrant is eligible to participate in only one government sponsored training program during her first five years of residency in Israel. The periodic probability of receiving an offer to participate in training depends on the immigrant's age at arrival and is given by,

$$
\begin{aligned}
& p t_{1}=\frac{\exp \left(p_{1}\right)}{1+\exp \left(p_{1}\right)} \text { if } A G E<40 \\
& p t_{2}=\frac{\exp \left(p_{2}\right)}{1+\exp \left(p_{2}\right)} \text { if } A G E \geq 40 .
\end{aligned}
$$

where $p_{1}$ and $p_{2}$ are parameters. ${ }^{27}$

The optimization problem (7) can be represented by a set of alternative-specific value functions, each obeying the Bellman (1957) equation:

$$
V_{a}(S(t), t)=U_{a t}+\beta E\left\{\max _{x \in A}\left(V_{x}(S(t+1), t+1) \mid S(t), d_{a t}=1\right\}, a \in A\right.
$$

where $V_{a}(S(t), t)$ is the maximum expected present value if alternative $a$ is chosen at time $t$, for a given element of the state space $S(t)$. As seen in (10), future decisions are assumed to be made optimally for any current choice $a, a \in A$.

Finally, under our setting, the state space in period $t$ can be written as,

$$
S(t)=\left\{d_{1 t-1}, d_{2 t-1}, d_{3 t-1}, d_{4 t-1}, k_{1 t-1}, k_{2 t-1} D T_{t}, S C, A G E, N, M, U O C, H e b_{t}, \varepsilon_{t}\right\}
$$

\section{Solution}

In each period the immigrant chooses one element from her choice set, $A$, for which the value function in (10) is maximized. The decision rules in a finite horizon model are not stationary and depend, among others, on the number of periods until retirement. The model is solved recursively from the last period back to the first. Denote by $\bar{S}(t)$ the deterministic elements of the state space

\footnotetext{
${ }^{27}$ The CT programs last between 1 to 3 quarters. To reduce computational burden in the estimation procedure we assume the actual length of the program is realized only after the immigrant's decision to participate in training is made. This implies that only the expected value of participation in training matters in the decision. Allowing the length of the training program to be realized before the decision is made, involves an increase of the state space by a factor of 3 . We also assume that programs of different length have the same impact on wages and on job-offer probabilities. This assumption is based on discussions we had with the administrators of the training programs. They indicated to us that the length of the program does not necessarily imply that the longer program covered more study-material, but rather, the same material was taught in at a different pace.
} 
(11). Consider an immigrant entering the last decision period $\mathrm{T}$ with $\bar{S}(T)$. The value functions at $\mathrm{T}$ are known up to a random draw from the multivariate normal distribution of the alternativespecific shocks,$\varepsilon_{T}$. Given a draw from this distribution, all the terminal value functions can be calculated and the immigrant chooses the alternative $a$ that gives her the highest realized value, $V_{a}(S(T), T)$.

However, when entering period T-1 with $\bar{S}(T-1)$, in order to calculate the value functions at $\mathrm{T}-1$, the immigrant has first to calculate,

$$
\begin{gathered}
E \max \left\{V_{1}(S(T), T), V_{2}(S(T), T), V_{3}(S(T), T), V_{4}(S(T), T) \mid S(T-1), d_{a T-1}\right\} \\
=\iint_{\varepsilon_{1 T}} \int_{\varepsilon_{2} T} \int_{\varepsilon_{3 T}} \int_{\varepsilon_{4 T}} \max \left\{V_{1}(S(T), T), V_{2}(S(T), T), V_{3}(S(T), T), V_{4}(S(T), T) \mid S(T-1), d_{a T-1}\right\} \\
f\left(\varepsilon_{1 T}, \varepsilon_{2 T}, \varepsilon_{3 T} \varepsilon_{4 T}\right) d \varepsilon_{1 T} d \varepsilon_{2 T} d \varepsilon_{3 T} d \varepsilon_{4 T}
\end{gathered}
$$

This calculation has to be done for every possible $a$, since each choice $a$ in $T-1$ leads to a different point in the state space in $T$. Thus, the Emax in (12) should be calculated at each of the potential four state space points at $T$ she can reach, given $\bar{S}(T-1)$ ). After calculating the Emax for each possible choice at $T-1$, the value functions at $T-1$ are known up to a random draw from the multivariate normal distribution of $\varepsilon_{T-1}$. Given a draw of $\varepsilon_{T-1}$, the immigrant chooses the alternative $a$ for which $V_{a}(S(T-1), T-1)$ is the highest. The same calculation is done as we move backwards. The value functions in period $t$ should be computed for any possible point, $\bar{S}(t+1)$ in the state space, that can arise given $\bar{S}(t)$ and the actual choice $d_{a t}$.

Under the assumption that the alternative-specific shocks have a multivariate normal distribution, (12) does not have a closed form expression. Full numerical computation of (12) requires high-dimensional integrations. Following Keane and Wolpin (1994), we use Monte Carlo integration to numerically approximate (12). That is, we take $D$ draws from the multivariate normal distribution of $\varepsilon_{T}$ and calculate for each draw the maximum of the value functions. The maximum values are averaged, implying

$$
\begin{aligned}
& E \max \left\{V_{1}(S(T), T), V_{2}(S(T), T), V_{3}(S(T), T), V_{4}(S(T), T) \mid S(T-1), d_{a T-1}\right\} \\
= & \frac{1}{D} \sum_{d=1}^{D} \max \left\{V_{1}(S(T), T), V_{2}(S(T), T), V_{3}(S(T), T), V_{4}(S(T), T) \mid S(T-1), d_{a T-1}\right\}
\end{aligned}
$$


Full solution of the dynamic programing problem, from the immigrant's arrival until retirement, for all potential points in the state space that may arise, involves an enormous computational burden, especially since we use quarterly and not annual data. To reduce this burden, we split the horizon to two sub-periods. During the first 20 quarters, the model is solved explicitly, as described above (See Appendix 1 for technical note). The value functions in the 21'st quarter, $V_{a}(S(21), 21)$ are assumed to be a parametrized function of the state space at the 20th quarter, $S(20)$. In particular, we assume the following terminal value function,

$$
\begin{aligned}
V_{a}(S(21), 21)= & \delta_{1} k_{1,20}+\delta_{2} k_{2,20}+\delta_{3 m}(60-A G E)+\delta_{4} D T_{20}+\delta_{5} \\
& +\delta_{6} d_{1,20}+\delta_{7} d_{2,20}+\delta_{8} S C+\delta_{9} N+\delta_{10} M+\delta_{11} U O C+\delta_{12} H_{e b_{20}}
\end{aligned}
$$

\section{Estimation Method}

The model is estimated using smooth maximum likelihood (SML) following McFadden(1989) and Keane and Wolpin (1997). Let $t_{i}$ be the length of time we observe immigrant $i$. Given data on choices of individual $i\left(d_{a t}^{i} ; t=1, \ldots, t_{i} ; a=1, . ., 4\right)$, and on her wage in occupation $j, w_{j t}^{i o}$, $\left(t=1, \ldots, t_{i}, j=1,2\right)$ if chosen, the solution of the dynamic programming problem serves as input in the estimation procedure. As such, all the parameters of the model enter to the likelihood function through their effect on the choice probabilities and wages. Given the observed variance in wages we allow for a multiplicative measurement error in observed wages (Keane and Wolpin, 1997), such that, the $\log$ of the observed wage of individual $i$ at time $t$ in occupation $j, \ln w_{j t}^{i o}$, is of the form: $\ln w_{j t}^{i o}=\ln w_{j t}^{i}+\eta_{j t}^{i}$, where $\eta_{j t}^{i} \sim N\left(0, \sigma_{\eta}^{2}\right)$ is the measurement error.

The likelihood for a sample of $I$ individuals is given by,

$$
L(\nu)=\prod_{i=1}^{I} \operatorname{Pr}\left(d_{a 1}^{i}, w_{j 1}^{i o}, d_{a 2}^{i}, w_{j 2}^{i o}, \ldots ., d_{a t_{i}}^{i}, w_{j t}^{i o} \mid S^{i}(0)\right)
$$

where $\nu$ is the vector of parameters to be estimated. Given the assumption of joint serial independence of the vector of errors, the likelihood function (15) can be written as a product of within-period conditional joint probabilities of the immigrant's choices and observed wage. These probabilities are computed from the solution of the dynamic programming as explained above. To achieve asymptotically efficient estimators using the simulated probabilities, we smooth the 
conditional probabilities. $^{28}$

\section{Identification}

Given data on the immigrant's choices in each period and on her wage in white or blue-collar occupation, all the wage parameters in (5), as well as $\gamma_{1 m}, \gamma_{2 m}, \gamma_{3 m},\left(-g_{1}+\gamma_{1 c}\right),\left(-g_{2}+\gamma_{2 c}\right)$ and $\left(-g_{3}+\gamma_{3 c}\right)$ can be identified. This result is due to the wage data as well as the joint transition and choice probabilities and wages. However, $g_{a}$ and $\gamma_{a c}$ can not be identified separately for $a=1,2,3$. In addition, lacking data on unemployment benefits and earnings during participation in training, we also can not identify $T W$ from $\gamma_{3 l}$ or $U B$ from $\gamma_{4 p}$. Therefore, we estimate the following utility parameters:

$$
\begin{aligned}
& U_{1 t}=w_{1 t}+\gamma_{1 m} M+\theta_{1 i} N+\gamma_{1 l} \\
& U_{2 t}=w_{2 t}+\gamma_{1 m} M+\theta_{1 i} N+\gamma_{2 l} \\
& U_{3 t}=t w+\gamma_{2 m} M+\theta_{2 i} N+\varepsilon_{3 t} \\
& U_{a t}=b+\gamma_{3 m} M+\theta_{3 i} N+\varepsilon_{4 t}
\end{aligned}
$$

Where $\theta_{1 i}=-g_{1}+\gamma_{1 c}, \theta_{2 i}=-g_{2}+\gamma_{2 c}, \theta_{3 i}=-g_{3}+\gamma_{3 c}, t w=T W+\gamma_{3 l}$ and $b=U B+\gamma_{4 l}$.

\section{Results}

This section presents the SML estimates of the structural parameters of the model. The solution of the dynamic programming problem serves as an input in the estimation procedure, as explained above. Hence, all the parameters of the model enter the likelihood function through their effect on the joint choice and wage probabilities. ${ }^{29}$ In this section we first discuss the fit of the estimated

\footnotetext{
${ }^{28}$ The smoothing function takes the standard logit form. For example, for the probability that the $x$ alternative, $x \in A$, was chosen from 4 possible alternatives $(a=1, . ., 4)$, we use the Kernel smoothing function: $\exp \left(\frac{\left(V_{x}(S(t), t)-\max \left(V_{a}(S(t), t)\right)\right.}{\tau}\right) / \sum_{a=1}^{4} \exp \left(\frac{\left(V a(S(t), t)-\max \left(V_{a}(S(t), t)\right)\right.}{\tau}\right)$. where $\tau$ is a parameter. This is the standard procedure in the literature.

${ }^{29}$ The program is written in FORTRAN90 code and it iterates between the solution of the Dynamic Programming (DP) and the calculation of the likelihood function. For each of the 502 immigrants in our sample, we calculate the Emax at each point in the state space that may arise during the 20 period planning horizon (that is for each possible combination of $k_{1}, k_{2}$, and $D T$ ). At each of these points, we use 150 simulated draws of the vector $\varepsilon$ to calculate the $E \max$. The state space increases linearly with the number of unobserved types. In this version of the model we assume there is no unobserved heterogeneity, as in an earlier version we have used 2 unobserved types and the proportion of type 1 converged to 0.98 which was not significantly different from 1 . Since the solution of the DP problem and the calculation of the likelihood function is done for each observation independently, we take advantage of the parallel processing features of super-computers. The program runs simultaneously on 8 or 16 or
} 
model to the actual aggregate labor states, the transitions between these states and wages. We then review the estimated parameters and their interpretations. The policy implications are discussed in the next section.

\subsection{Model Fit}

Given the estimated parameters of the model (to be discussed later) and the assumed random errors we simulated the one quarter ahead predicted proportion of the initial 502 women in our sample for each of the five labor market states for the duration of each observation in the data. ${ }^{30}$ In Table 6 we report the actual and the predicted proportion of females in each labor market state to show the fit of the estimated model to the aggregate data. Table 6 also presents the simple $\chi^{2}$ test of the fit for each quarter and for each choice for all the periods.

The estimated model fits the aggregate proportions extremely well and succeeds in replicating the qualitative and quantitative patterns of the data. The $\chi^{2}$ goodness of fit test confirm this observation. The estimated model predicts that $9.4 \%(18.6 \%)$ of the immigrants will be employed in $\mathrm{BC}$ during the first (third) quarter in Israel, compared to $6.4 \%$ (26.3\%) in the data. The tests confirm that the predicted and observed choices are statistically different only in the first and third quarters. No significant differences are found by simple $\chi^{2}$ goodness of fit test between actual and predicted choices for each alternative, separately, and for the whole model.

The predicted pattern of participation in training is consistent with the data. The model predicts the peak in training attendance during the fourth quarter, but this proportion is only $14.2 \%$ compared to the observed participation rate of $16.9 \%$. Furthermore, the estimated model predicts that 198 immigrants choose to attend training during the sample period compared to 218 immigrants in our sample.

It should be noted that the goodness of fit of the estimated model to the aggregated choices does not necessarily ensure that the model well explains each individual's choices. Here, the model correctly predicts 5,474 choices out of the 7,205 observed choices which implies that the estimated model "explains" (pseudo $R^{2}$ ) 76\% of the immigrants' choices within the sample period.

32 processors on IBM and Silicon Graphics (Origin2000) super computer at Tel-Aviv University and on a Silicon Graphics super-computer at Boston University.

${ }^{30}$ The predictions in this section are based on one step ahead predictions. As noted in Keane and Wolpin (1994), maximum-likelihood estimation of the model under the assumption of serial independence is based on one-step ahead forecasts of the conditional transition probabilities. This predictions are based on 50 one-step ahead simulations of the choices of each of the 502 women in our sample aggregated over the estimated types. 
Table 6: Actual and Predicted Choice Distribution

\begin{tabular}{|c|c|c|c|c|c|c|c|c|c|c|}
\hline \multirow[t]{2}{*}{ Quarter } & \multirow[t]{2}{*}{ Number of Obs. } & \multicolumn{2}{|c|}{ White-Collar } & \multicolumn{2}{|c|}{ Blue-Collar } & \multicolumn{2}{|c|}{ Training } & \multicolumn{2}{|c|}{ Unemployed } & \multirow[t]{2}{*}{$\overline{\chi^{2}(3)^{*}}$} \\
\hline & & Actual & Predicted & Actual & Predicted & Actual & Predicted & Actual & Predicted & \\
\hline 1 & 502 & 0.010 & 0.016 & 0.064 & 0.094 & 0.002 & 0.010 & 0.924 & 0.881 & 6.99 \\
\hline 2 & 502 & 0.026 & 0.024 & 0.149 & 0.159 & 0.016 & 0.016 & 0.809 & 0.801 & 0.44 \\
\hline 3 & 495 & 0.044 & 0.061 & 0.263 & 0.186 & 0.121 & 0.101 & 0.572 & 0.653 & 24.76 \\
\hline 4 & 476 & 0.069 & 0.067 & 0.299 & 0.322 & 0.169 & 0.142 & 0.463 & 0.470 & 3.33 \\
\hline 5 & 466 & 0.082 & 0.099 & 0.333 & 0.367 & 0.150 & 0.135 & 0.436 & 0.399 & 5.22 \\
\hline 6 & 457 & 0.130 & 0.116 & 0.372 & 0.374 & 0.116 & 0.090 & 0.409 & 0.420 & 4.33 \\
\hline 7 & 446 & 0.132 & 0.150 & 0.399 & 0.419 & 0.085 & 0.079 & 0.383 & 0.352 & 2.89 \\
\hline 8 & 430 & 0.147 & 0.163 & 0.449 & 0.440 & 0.072 & 0.063 & 0.333 & 0.335 & 1.38 \\
\hline 9 & 422 & 0.168 & 0.166 & 0.472 & 0.486 & 0.059 & 0.062 & 0.301 & 0.287 & 0.53 \\
\hline 10 & 417 & 0.194 & 0.185 & 0.496 & 0.487 & 0.046 & 0.048 & 0.264 & 0.281 & 0.76 \\
\hline 11 & 412 & 0.194 & 0.223 & 0.517 & 0.507 & 0.032 & 0.041 & 0.257 & 0.228 & 4.12 \\
\hline 12 & 408 & 0.213 & 0.223 & 0.525 & 0.515 & 0.020 & 0.029 & 0.243 & 0.233 & 1.75 \\
\hline 13 & 386 & 0.233 & 0.241 & 0.536 & 0.536 & 0.013 & 0.018 & 0.218 & 0.205 & 0.98 \\
\hline 14 & 354 & 0.251 & 0.266 & 0.537 & 0.540 & 0.025 & 0.023 & 0.186 & 0.172 & 0.81 \\
\hline 15 & 321 & 0.252 & 0.259 & 0.533 & 0.539 & 0.034 & 0.019 & 0.181 & 0.184 & 4.25 \\
\hline 16 & 281 & 0.256 & 0.267 & 0.562 & 0.545 & 0.021 & 0.032 & 0.160 & 0.157 & 1.30 \\
\hline 17 & 207 & 0.295 & 0.275 & 0.541 & 0.560 & 0.005 & 0.015 & 0.159 & 0.150 & 0.55 \\
\hline 18 & 127 & 0.323 & 0.299 & 0.528 & 0.528 & 0.008 & 0.008 & 0.142 & 0.165 & 0.67 \\
\hline 19 & 63 & 0.397 & 0.381 & 0.444 & 0.444 & 0.000 & 0.000 & 0.159 & 0.175 & 0.13 \\
\hline 20 & 30 & 0.433 & 0.433 & 0.400 & 0.367 & 0.000 & 0.000 & 0.167 & 0.200 & 0.26 \\
\hline$\chi^{2}(19)^{*}$ & & & 1324 & & 4095 & & 8341 & & 3538 & \\
\hline
\end{tabular}

*The relevant critical values are $\chi^{2}(3)=7.81$ and $\chi^{2}(19)=30.14$. In the training column there are 14 d.f. since in some of the cells there are less than 5 immigrants. Therefore, the critical value for this column is 23.68 . In the 1 st, 17 th and 20 th quarters there are 2 d.f. and the relevant critical value is 5.99.

Table 7 presents the actual and predicted quarter to quarter transitions between the four states of the model based on the same simulations as above. ${ }^{31}$ The estimated model captures the dominance of the elements on the diagonal remarkably well. However, it produces too few transitions from the two employment states to training.

The fit of the model to the mean wage by time in Israel, occupation-specific experience and training is presented in Table 8 . The estimated model predicts very well the dynamic pattern and the level of wages by occupation. The substantial growth in wages by time since arrival in WC occupations is somewhat underpredicted by the model but the flat pattern of wages in $\mathrm{BC}$ occupation is well documented by the model. The same pattern by occupation specific experience is also well captured by the model. Finally, the observed mean wage growth of $27 \%$ due to training

\footnotetext{
${ }^{31}$ The total number of quarter to quarter transitions is $7,205-502=6,703$.
} 
in WC jobs is very well predicted by the model. However, the almost zero return to training in $\mathrm{BC}$ jobs is captured by a predicted small decline in wages.

Table 7: Actual and Predicted Transitions*

\begin{tabular}{l|rrrrrrrr|r}
\hline \hline & \multicolumn{2}{c}{ To } & \multicolumn{2}{c}{ White-Collar } & \multicolumn{2}{c}{ Blue-Collar } & \multicolumn{2}{c|}{ Training } & \multicolumn{2}{c|}{ Unemployment } & Total \\
\hline From & Actual & Predicted & Actual & Predicted & Actual & Predicted & Actual & Predicted & \\
\hline White-Collar & 918 & 932 & 7 & 0 & 12 & 2 & 23 & 26 & 960 \\
Blue-Collar & 14 & 12 & 2414 & 2437 & 51 & 29 & 120 & 121 & 2599 \\
Training & 33 & 43 & 71 & 67 & 222 & 208 & 105 & 113 & 431 \\
Unemployment & 101 & 130 & 330 & 313 & 154 & 162 & 2128 & 2108 & 2713 \\
\hline Total & 1066 & 1109 & 2822 & 2822 & 439 & 397 & 2376 & 2373 & 6703 \\
\hline \hline
\end{tabular}

$\chi^{2}=79.855$. The critical value $\chi^{2}(14)=29$

Table 8: Actual and Predicted Accepted Wages by Time Since Migration, Experience and Participation in Training

\begin{tabular}{l|cccc}
\hline \hline \multirow{2}{*}{ Tenure in Israel (quarters) } & \multicolumn{2}{|c}{ WC } & \multicolumn{2}{c}{ BC } \\
$1-4$ & Actual & Predicted & Actual & Predicted \\
\cline { 2 - 5 } $5-8$ & \multicolumn{3}{c}{} & \\
$9-12$ & 12.52 & 14.48 & 10.22 & 9.35 \\
$13-16$ & 17.26 & 16.63 & 10.36 & 9.74 \\
Experience by occupation (quarters) & 17.92 & 19.37 & 9.73 & 9.82 \\
$0-4$ & 26.17 & 21.82 & 10.56 & 9.69 \\
$5-8$ & 19.88 & 16.87 & 10.63 & 9.58 \\
$9-12$ & 18.70 & 21.36 & 9.81 & 9.89 \\
$13-16$ & 25.85 & 24.12 & 10.21 & 9.89 \\
Participation in training & 25.13 & 26.94 & 11.53 & 9.98 \\
Before training & & & & \\
After training & 18.10 & 18.28 & 10.07 & 9.79 \\
\hline \hline
\end{tabular}

Wage per hour in July 1995 NIS.

\subsection{Estimated Parameters}

\section{Wage Parameters (Table 9)}

The occupation-specific wage functions were estimated according to equation (5) with no quadratic elements $\left(\alpha_{3 j}=\alpha_{5 j}=0, j=1,2\right)$. The estimated parameters are very close to the OLS parameters in Table 5. We find that immigrants from the former Soviet Union have (almost) zero return to 
their imported human capital in the form of schooling and experience when we condition on investment in local accumulated human capital. The return to schooling is $2.3 \%(0.7 \%)$ in WC (BC) occupation and not significant at the $5 \%$ level. The impact of experience in the country of origin (using age at arrival) is also statistically insignificant in both occupations. The finding that Russian female immigrants do not receive return to the human capital that they brought from the former Soviet-Union is consistent with other findings on Russian male immigrants (Cohen and Eckstein, ,2002) and Eckstein and Weiss, 1998).

The distinction between $\mathrm{BC}$ and $\mathrm{WC}$ occupation-specific experience is important for the analysis of the sources of immigrants' wage growth. An additional quarter of WC experience significantly increases WC wage by $3.9 \%$. WC work experience also has a large effect on $\mathrm{BC}$ wage $(2.7 \%)$, but this impact is statistically insignificant. The return to $\mathrm{BC}$ experience in both $\mathrm{BC}$ and $\mathrm{WC}$ occupations is small and not significant. This last finding implies that the wage of immigrants who were absorbed in $\mathrm{BC}$ jobs is not expected to grow as the immigrants accumulate experience in these low-skilled jobs. On the other hand, wage in WC jobs grows rapidly in the short run with the accumulation of WC work experience. Hence, wage growth does not depend solely on previous employment, but rather also on the occupation specific experience. Studies that use age (or tenure in the destination country) as a proxy for experience, ignore the possibility that occupation-specific experience may have a substantially different impact on wage growth.

Knowledge of Hebrew has a positive and significant return in both $\mathrm{WC}$ and $\mathrm{BC}$ occupations. The Hebrew index variable ranges between 1 (no knowledge) and 4 (full control of Hebrew), implying that the return of obtaining full fluency in Hebrew is $18 \%$ in WC jobs and $24 \%$ in BC jobs.

The return to training in terms of a wage increase also depends on the immigrant's occupation. The wage-return to training in WC jobs $\left(a_{61}\right)$ is $19.5 \%$ and is significantly different from zero at $5 \%$ level. The OLS estimator from a similar specification is $16.1 \%$ and insignificant. Thus, the OLS estimate is downward biased due to the selection to training and due to occupational choice. The wage-return to training in $\mathrm{BC}$ jobs $\left(a_{62}\right)$ is not statistically different from zero. This result is consistent with Cohen and Eckstein(2002) surprising result of the high return to male training in WC jobs.

The finding that training has no impact on wage in $\mathrm{BC}$ jobs is consistent with the prevalent finding in the US that the return to government-sponsored training is close to zero. One of the main explanations in the training literature for the small private gain from training is that government- 
sponsored training is usually targeted towards relatively unskilled and less able individuals who work in low-skill jobs and are poorly paid. As Heckman, LaLonde and Smith (1999) argue, evidence on the complementarity between the return to training and skill (education) in the private sector suggests that the return to training in the public sector should be relatively small. When the study focuses on local workers, it is reasonable that the correlation between the individual's education and the skills required for her job is high. Formally, the person uses her education in carrying out her job. However, this correlation is likely to be low for highly-educated immigrants who have just arrived in the new labor market and who may experience occupational downgrading. Our findings suggest that only immigrants who have succeeded in climbing up the occupational ladder, receive a high return to their investment in training.

\section{Job Offer Parameters (Table 9)}

The estimated parameters imply that job-offer probabilities by occupation are sensitive to the current labor market state and to the human capital stocks. The probability of job retention in the same occupation is close to one, but job-offer rates are much lower for WC and BC if the current state is different. Moreover, the probability of an unemployed immigrant to receive a job-offer in either occupation is higher than from employment in the other occupation $\left(b_{12 j}<b_{11 j}\right), j=1,2$. These results are consistent with widely used assumptions on job-offer rates in models with searchon-the-job.

Imported human capital that had almost no effect on wages, turn out to have a significant and important impact on WC job opportunities. An additional year of schooling substantially increases the probability of receiving a WC job offer, but has no effect on job-offer probabilities in BC. For example, an unemployed immigrant with 15 years of schooling is facing a WC (BC) job-offer probability which is $15.7 \%(0.13 \%)$ higher than the probability of a similar immigrant with 14 years of schooling. However, age at arrival has zero impact on the job-offer probabilities in both occupations. Furthermore, an immigrant who worked in a WC job in the Soviet-Union receives a WC job-offer with probability which is $43 \%$ higher than that of an immigrant who held in a BC job in the former Soviet-Union. Similarly, the probability of an immigrant who worked in a BC job in the Soviet-Union to receive a BC job offer is $27 \%$ higher than that of an immigrant who worked in WC prior to migration. ${ }^{32}$

\footnotetext{
${ }^{32}$ All the figures in this paragraph refer to job offer probabilities of an unemployed immigrant who was 38 at arrival, has 14 years of schooling and no experience or training.
} 
Table 9: Estimated Occupation-Specific Wage and Job Offer Probability Parameters

\begin{tabular}{|c|c|c|}
\hline & $\overline{\mathrm{WC}}, j=1$ & $\mathrm{BC}, j=2$ \\
\hline \multicolumn{3}{|l|}{ Wage Parameters } \\
\hline$\alpha_{o j}-$ constant & $\begin{array}{l}1.7615 \\
(0.007)\end{array}$ & $\begin{array}{l}1.8350 \\
(0.0429)\end{array}$ \\
\hline$\alpha_{1 j}$ - years of schooling & $\begin{array}{l}0.0230 \\
(0.0128)\end{array}$ & $\begin{array}{l}0.0025 \\
(0.0071)\end{array}$ \\
\hline$\alpha_{2 j}$ - experience $\mathrm{WC}$ & $\begin{array}{c}0.0388 \\
(0.012)\end{array}$ & $\begin{array}{l}0.0269 \\
(0.0236)\end{array}$ \\
\hline$\alpha_{4 j}$ - experience BC & $\begin{array}{l}0.0006 \\
(0.0234)\end{array}$ & $\begin{array}{l}0.0045 \\
(0.0041)\end{array}$ \\
\hline$\alpha_{6 j}$ - training & $\begin{array}{l}0.1951 \\
(0.0882)\end{array}$ & $\begin{array}{l}-0.0149 \\
(0.0334)\end{array}$ \\
\hline$\alpha_{7 j}$ - age at arrival & $\begin{array}{l}0.0054 \\
(0.0045)\end{array}$ & $\begin{array}{l}0.0023 \\
(0.0022)\end{array}$ \\
\hline$\alpha_{8 j}-$ Hebrew & $\begin{array}{l}0.0620 \\
(0.0165)\end{array}$ & $\begin{array}{l}0.0802 \\
(0.0130)\end{array}$ \\
\hline \multicolumn{3}{|l|}{ Job-Offer Parameters } \\
\hline$b_{10 j^{-}}$attended training at $t-1$ & $\begin{array}{r}-5.8560 \\
(0.2124)\end{array}$ & $\begin{array}{r}-1.4962 \\
(0.3808)\end{array}$ \\
\hline$b_{11 j}$ - unemployed at $t-1$ & $\begin{array}{r}-6.6306 \\
(0.1834)\end{array}$ & $\begin{array}{r}-2.2585 \\
(0.3369)\end{array}$ \\
\hline$b_{121^{-}}$worked in BC at $t-1$ & $\begin{array}{r}-9.2383 \\
(0.2916)\end{array}$ & - \\
\hline$b_{122^{-}}$worked in WC at $t-1$ & - & $\begin{array}{l}-4.3348 \\
(0.5684)\end{array}$ \\
\hline$b_{2 j^{-}}$years of schooling & $\begin{array}{l}0.1551 \\
(0.0200)\end{array}$ & $\begin{array}{l}0.0015 \\
(0.0201)\end{array}$ \\
\hline$b_{3 j^{-}}$age at arrival & $\begin{array}{l}0.0015 \\
(0.0079)\end{array}$ & $\begin{array}{l}0.0080 \\
(0.0056)\end{array}$ \\
\hline$b_{4 j^{-}}$training & $\begin{array}{l}1.0797 \\
(0.0048)\end{array}$ & $\begin{array}{l}0.7897 \\
(0.1228)\end{array}$ \\
\hline$b_{5 j^{-}}$WC in Soviet Union & $\begin{array}{l}0.8719 \\
(0.1035)\end{array}$ & $\begin{array}{c}-0.2684 \\
(0.1198)\end{array}$ \\
\hline$b_{6 j}$ - experience in occupation $j$ & $\begin{array}{l}0.1936 \\
(0.0512)\end{array}$ & $\begin{array}{l}0.0434 \\
(0.0229)\end{array}$ \\
\hline$b_{7 j^{-}}$Hebrew & $\begin{array}{r}0.2420 \\
(3.1608) \\
\end{array}$ & $\begin{array}{r}0.0314 \\
(0.0183) \\
\end{array}$ \\
\hline$s_{j}-$ separation rate from occupation $j$ & $\begin{array}{l}0.0336 \\
(0.0068)\end{array}$ & $\begin{array}{l}0.0515 \\
(0.0039)\end{array}$ \\
\hline
\end{tabular}

S.E. in parenthesis ( outer product of the numerical first derivatives of the SML)

The impact of accumulated WC experience on WC job offer probability is greater than the impact of $\mathrm{BC}$ experience on $\mathrm{BC}$ job offer probability. In Table 10 we demonstrate the impact of immigrant's occupation-specific experience on the job-offer probabilities from a state of unemployment with and without training. We consider a female immigrant with 14 years of schooling, was 38 years old at arrival, has a knowledge of Hebrew index of 3 and worked in a WC job prior to migration. As expected, the estimated model predicts a considerable difference between the availability of $\mathrm{BC}$ and $\mathrm{WC}$ job offers. At arrival, the immigrant described above each quarter receives a job offer in $\mathrm{WC}(\mathrm{BC})$ occupation with a probability of $0.057(0.108)$. This probability is not 
expected to change as long as the immigrant is unemployed and has not accumulated local skills as work experience, training and knowledge of Hebrew. An additional quarter of WC experience increases WC job offer probability of an unemployed immigrant by $5.5 \%-20 \%$, while a quarter of $\mathrm{BC}$ work experience increases $\mathrm{BC}$ job offer probability by only $3.4 \%-4 \%{ }^{33}$ The large impact of WC experience on WC job offer probability leads to a situation where the probability of an unemployed immigrant who had already accumulated 9 quarters of WC experience receives a WC job offer is higher than the probability of an immigrant who accumulated 9 quarters of BC experience receiving a BC job offer (see Table 10 columns (1) and (4)).

The effect of training on the job-offer probabilities can be broken down to a permanent effect, $b_{4 j}, j=1,2$, and a transitory effect in the quarter following graduation from the training program, $b_{10 j}$. Both coefficients indicate that training has a significant positive impact on job-offer probabilities in both occupations, but a much larger effect on WC jobs. The permanent effect of training on WC job offer probabilities ranges between $165 \%$ for an unemployed immigrant without WC experience to $20 \%$ for an immigrant who has accumulated 20 quarters of WC experience. The permanent effect of training on BC job offer probabilities is estimated by $73 \%-94 \%$. Since most of the female immigrants who participated in training had no prior experience of any kind in Israel, the permanent effect of training on their job offer probabilities is enormous.

In addition, training also has a large and significant transitory impact on the probabilities in the quarter following graduation from the training program. The probability of an unemployed immigrant with no work experience receiving a WC (BC) job offer in the subsequent quarter after training is 4.9 (3.4) times higher than the probability of an immigrant who has not attended training (Table 10). Given the minor probability of receiving a WC job offer, participation in training seems like an unavoidable step in the process of WC job-search. Moreover, in the absence of WC experience, the effect of training on a WC job offer probability in the quarter following training is twice the permanent effect of training.

What is the source for the immediate transitory impact of training on job offer probabilities? According to Brookdale surveys, during the training program about $46 \%$ of the participants visited factories or institutes that are related to the study program. These visits involved meetings with potential employers, suggesting that training has an additional premium after graduation from

\footnotetext{
${ }^{33}$ The contribution of an additional quarter of work experience on job offer probabilities is not constant due to the logistic form of these probabilities. This impact decreases with accumulated experience, other things being equal.
} 
the program. In addition, about $55 \%$ of the trainees reported that the CT program also involved explanations on the Israeli labor market and on employment opportunities. Therefore, it is possible that the effect of training on the job-offer probabilities reflects not only the effect of vocational skills' acquisition, but also acquisition of job search skills. Although we cannot distinguish between these two effects, we believe that the finding that training has a different impact on a WC joboffer probability than on a BC job-offer probability, indicates that the immigrants indeed obtain occupational skills and not only job-search skills.

The estimated quarterly separation rate (Table 9) from WC (BC) jobs is $3.36 \%(5.15 \%)$. These rates are high and it indicates the high mobility of immigrants in the new labor market which is similar to the mobility of young workers.

Comment: The labor and immigration literature focuses on the wage growth and the earning return to imported and locally accumulated human capital. The model here follows the dynamic labor supply literature (search and labor force participation models) with emphasis on the job-offer probabilities as a source for friction in the labor market which may depend on the human capital characteristics of the individual. In this framework the wage data identifies the earning growth conditional on the return to human capital that has been imported or locally accumulated. The labor market transitions to jobs and training participation identify the conditional impact of the human capital stocks on the job-offer opportunities which may end up to be of greater value to the individual than the potential return if the job is not received. It turned out that the increase in job-offer opportunities due to training is more important to this human capital investment than the impact of training participation on the potential wage. The reason for that is that the earning return to training is realized only if the immigrant is working in a WC job, which is a low probability event.

\section{Training Offer Probability Parameters}

The model predicts a substantial difference in the availability of training offer probabilities with respect to the immigrant's age at arrival (Table A1). An immigrant who was 40 years old or younger at arrival, each quarter receives an offer to participate in training with a probability of 0.136. However, an immigrant who was over 40 years old at migration, receives such an offer with a probability of only 0.058 . This difference reflects the selection made by the government training administrators in providing training programs and the self selection of immigrants of different age. 
Table 10: Estimated job-offer probabilities in White-Collar and Blue-Collar occupations*

\begin{tabular}{c|cccccc}
\hline \hline \multirow{2}{*}{$\begin{array}{c}\text { Occupation } j \\
\text { experience }\end{array}$} & \multicolumn{3}{|c}{ WC job-offer probability } & \multicolumn{3}{c}{ BC job-offer probability } \\
\cline { 2 - 6 } $\begin{array}{c}\text { in quarters) } \\
\text { no }\end{array}$ & $\begin{array}{c}\text { a quarter after } \\
\text { training }\end{array}$ & $\begin{array}{c}\text { after } \\
\text { training }\end{array}$ & $\begin{array}{c}\text { no } \\
\text { training }\end{array}$ & $\begin{array}{c}\text { a quarter after } \\
\text { training }\end{array}$ & $\begin{array}{c}\text { after } \\
\text { training }\end{array}$ \\
4 & 0.057 & 0.279 & 0.151 & 0.108 & 0.365 & 0.211 \\
8 & 0.116 & 0.456 & 0.279 & 0.126 & 0.406 & 0.247 \\
12 & 0.222 & 0.645 & 0.456 & 0.147 & 0.448 & 0.275 \\
16 & 0.382 & 0.798 & 0.645 & 0.170 & 0.491 & 0.311 \\
20 & 0.573 & 0.895 & 0.798 & 0.196 & 0.535 & 0.349 \\
$*$ & 0.744 & 0.949 & 0.895 & 0.224 & 0.577 & 0.389 \\
The job offer probabilities are set for an unemployed immigrant with 14 years of schooling.
\end{tabular}

\section{Terminal Value Parameters}

The terminal value embodies the expected future value the immigrant receives after five years in Israel. We assume that this value depends on the space state in the 20th quarter and specifically, on the work experience accumulated by the immigrant in $\mathrm{BC}$ and $\mathrm{WC}$ up to the 20th quarter and her participation in training. Every quarter of $\mathrm{WC}(\mathrm{BC})$ experience increases the terminal value by 633 (520) NIS (see Table A1). As expected the terminal value decreases with age at arrival as the labor life-cycle of the immigrant is shorter. Training increments the terminal value by 1,400 NIS. This means that the value of training in terminal value is larger than the value of two quarters of work experience in $\mathrm{WC}$ and is slightly smaller than the value of three quarters of work experience in BC. Every unit of Hebrew knowledge (the units range between 1 to 4) contributes 35.98 NIS to the terminal value. Work in WC in the 20th quarter increases the terminal value by 380 NIS. This premium for work in $\mathrm{WC}$ reflects the fact that an immigrant who is employed in $\mathrm{WC}$ is expected to continue working in this occupation with a high probability and earn a high wage.

\section{Utility Parameters}

The utility estimates (see Table A1) show that the immigrants do not like training and unemployment. However, the disutility from attending training is much smaller than the disutility while being unemployed. This suggests that even if there is no gain associated with training, the immigrant will prefer training to being unemployed as long as training is available. In addition, we find a negative correlation between the preferences shocks in unemployment and training (panel d in Table A1). This correlation may make training more appealing while unemployed. 


\section{The Gain from Training}

The main reason for estimating the model is to quantitatively evaluate the individual and the social benefit from training as well as evaluating alternative economic policies that are potentially important but have not been actually implemented. ${ }^{34}$ We quantitatively evaluate, by counterfactual experiments using the estimated model, the predicted outcomes of training and, as an alternative, two other Active Labor Market Policies (ALMP), that are often considered by the government. Specifically, we study the effect of four alternative policies on several predicted outcomes: employment by occupation; unemployment dynamics; participation in training programs; the expected present value of utility (individual benefit) and the expected annual earnings over the first five years after migration (gross social benefit). ${ }^{35}$

The four policy experiments that we consider are:

Policy experiment A: No training program is offered to female immigrants. We model it by setting the quarterly probability to receive a training offer to be equal to zero regardless of age. This is compared to the estimated offer rates ("benchmark economy") that are 0.136 for females younger than 40 at arrival and 0.056 for a females older than 40 at arrival.

Policy experiment B: Each immigrant has free access to training. Free access to training means that the government offers many courses all the time. We model it by setting the quarterly probability to receive a training offer to be equal to one regardless of age. ${ }^{36}$

Policy experiment C: White-collar job offer probability is doubled for immigrants who had no prior experience in WC jobs and stays the same for all others. ${ }^{37}$ Here we assume that the government is able to directly subsidize employers who hire immigrants without prior experience in WC jobs. This subsidy is assumed to be set such that employers would increase the efforts to find these individuals. We assume that the increase in these efforts imply that the offer probability is doubled only for these immigrants.

Policy experiment D: The government subsidizes the wage offered to workers in WC jobs

\footnotetext{
${ }^{34}$ This statement is based on the classic papers by Marschak (1953) and Lucas (1976) who emphasized the need for measurement of the impact of policies.

${ }^{35}$ We ignore the cost of the program due to lack of information but we discuss it in evaluating the quantitative outcomes of the counterfactual.

${ }^{36}$ This holds except for the first two quarters in Israel where only immigrants with prior knowledge of Hebrew are allowed to enter the training programs as is the standard prerequisite.

${ }^{37}$ For example, for an unemployed immigrant with the following specification; no prior training, worked in WC job in the USSR, age at arival is 38,14 years of schooling and Hebrew index of 3 , the probability of a WC job offer in Israel increases from $5.7 \%$ to $11.4 \%$ (see first row in Table 10).
} 
during the first two years in Israel. Specifically, we assume that offered wages are higher than in the benchmark by 6 NIS (1995 prices) during the first year and by 3 NIS during the second year. ${ }^{38}$

Each of these policies emphasizes different aspects by which one can affect the employment and welfare of female immigrants. To evaluate the effect of each policy we simulate each "economy" using our random sample of 502 female immigrants assuming that all immigrants stay in the sample for 20 quarters (five years). ${ }^{39}$ The "benchmark economy" consists of the simulation using the estimated parameters of the model reported above. Table 11 reports the predicted policy effect on labor market outcomes, and Table 12 reports the predicted effects on mean accepted wages, annual earnings per-worker (social benefit) and expected present value (individual welfare).

Particular attention should be given to the calculation of the private and the social benefits estimated for each case. The absolute value of expeted utility is the present value of an hour of leisure in 1995 NIS. The private benefit of each policy is measured by the change in this average expected present value of utility at arrival, over the sample of 502 immigrants, due to the policy relative to the benchmark. The social benefit suppose to measure the increase in output minus the cost of the program for the sample. We use the present value of earnings of each immigrant as the measure for her output and we ignore the cost of the program due to data limitations. The present value of earnings is presented in annual terms (1995 NIS) per immigrant assuming that in each of the 20 quarters in Israel the immigrant works 500 hours. ${ }^{40}$

The impact of policy experiment A, which eliminates the availability of training, on female immigrants' unemployment and employment in WC jobs after five years in Israel is substantial (Table 11). Policy experiment B, that makes training availabale in probability one, would increase participation in training by $61 \%$ (from 249 to 401 females), where participation mainly occures during the first year. Since training increases job offer probabilities in both occupations, this intervention has a positive effect on employment, in general, and on employment in WC jobs, in particular. After five years in Israel, unemployment is predicted to fall from $17.9 \%$, in the benchmark economy to $13.3 \%$, and the share of the employed in WC jobs increases by five percent

\footnotetext{
${ }^{38}$ Actually the offered wage during the first year for a WC job is, $w_{1 t}=\exp \left\{\alpha_{01}+\alpha_{11} S C+\alpha_{21} k_{1 t-1}+\alpha_{41} k_{2 t-1}+\right.$ $\left.\alpha_{61} D T_{t}+\alpha_{71} A G E+\alpha_{81} H e b_{t}+\varepsilon_{1 t}\right\}+6$, and during the second year the 6 is replaced by 3 .

${ }^{39}$ This assumption is needed in order to avoid sample selection impact that is based on the time each immigrant has arrived in Israel relative to the time of the interview.

${ }^{40}$ The annual earnings is calculated by: $\frac{4}{502 x 5} \sum_{i=1}^{502} \sum_{t=1}^{20} \beta^{t}\left(w_{i 1 t}+w_{i 2 t}\right) 500$, and it is reported in Table 12 .
} 
while the employment proportion in $\mathrm{BC}$ jobs decreases by two percent.

The effect of policy experiment $\mathrm{C}$ after a year, is a substantial increase in employment in whitecollar jobs, and a decrease in unemployment. However, this policy also lowers the employment in blue-collar jobs (Table 11). After five years, the share of female immigrants employed in WC jobs increases to $48.8 \%$, while unemployment declines to $13.9 \%$, and employment in $\mathrm{BC}$ jobs declines to $37.3 \%$. Participation in training slightly increases by about one percent (20 immigrants). Note that, policy experiment $\mathrm{C}$ has almost the same effect as policy experiment $\mathrm{B}$ on unemployment, but it has a much larger effect on the proportion of female immigrants working in WC jobs. Policy experiment $\mathrm{D}$ has no effect on the choice distribution of the immigrants and, therefore, has no effect on employment in WC jobs. The reason this policy is ineffective is that immigrants prefer WC jobs even without the wage subsidy, and the main reason they are not employed in WC jobs is the low offer probability (low availability) of these jobs.

Policy A has small negative effect on wages in WC after 20 quarters, but no effect on wages in $\mathrm{BC}$ jobs (Table 12), while policy experiment $\mathrm{B}$ has a large positive effect on accepted wages in white-collar jobs and a small positive effect on accepted wage in blue-collar jobs. There are two sources for the increase in WC wages. First, immigrants who participated in training and find a $\mathrm{WC}$ job earn more due to the high wage return to training in $\mathrm{WC}$ jobs. Second, immigrants who work in WC jobs accumulate more experience in WC jobs and enjoy the high return to this specific experience. The wage increase is of about 3 NIS which is 18 to 13 percent growth relative to the benchmark economy depending on the time since arrival. Since the return to training and to BC experience in $\mathrm{BC}$ jobs is almost zero, this intervention has no significant effect on accepted wage in BC jobs.

Policy experiment $\mathrm{C}$ has no effect on the mean accepted wage in $\mathrm{BC}$ and a small effect on mean accepted wages in WC jobs. This policy accelerates accumulation of WC experience, which has a positive effect on wages in WC. However, more immigrants with less skills (education) are now employed in WC jobs. This selection process implies a negative effect that offsets part of the positive effect of more WC experience on wages in WC jobs. Policy experiment D has no effect on labor market outcomes and wages (Table 12). As such, this policy consists of a pure transfer of income to immigrants in WC jobs during the first two years in Israel, but without any real impact on the economy.

The social and the private benefits from the policies are reported at the bottom of Table 12 . 
The elimination of training programs (policy A) is predicted to reduce annual output per immigrant by 18 percent due to the reduction in employment in $\mathrm{WC}$ jobs and the increase in unemployment. Free access to training (policy B) increases the average yearly earnings per immigrant by about 13 percent. This average increase in earnings due to training is almost double the estimated return to a year of schooling for native Israelis (See Eckstein and Weiss, 2004). The average duration of training is about half a year and the cost is lower than standard schooling. Hence, it is most likely that the model predicts a very high social return to the training programs, assuming that the increase in earnings reflect marginal product and, therefore, are proportional to the increase in output. ${ }^{41}$ Overall, the gain from free access to training in comparison to no training implies an annual earnings growth of $31.3(=13.1+18.2)$ percent.

The large reduction (41\%) in welfare of female immigrants from eliminating the training program (policy A) and the large increase (50\%) in welfare from free training (policy B) reveal the large average gain from training. However, this gain has a large variance among the female immigrants. The largest gain is obtained by older and less educated females that moved from unemployment to employment due to their participation in training. The fact that the older females at the benchmark economy had a very low rate of training offers, created a large potential gain as training become available in probability one. This result suggests that intervention policies have a larger impact on extensive margines (unemployment to employment), then on intensive magines (higher rate of WC jobs).

Policy $\mathrm{C}$ implies a predicted annual increase in earnings per female immigrant of about 20 percent, which is a high social return to this policy, but lower than that of free training. The private gain from policy $\mathrm{C}(24 \%)$ is also lower than the one obtained from free training and it is very close to the increase in earnings. The main advantage of the training expansion policy $\mathrm{B}$, compared to the policy $\mathrm{C}$, is that training directly affects both employment and wage (productivity), while policy $\mathrm{C}$ affects only employment in WC jobs and the effect on wages is only secondary through accumulation of WC experience. Policy D has no social or private gain, eventhough money has been transfered but only to a small fraction of females.

\footnotetext{
${ }^{41}$ When calculating the annual present value of earnings only of employed immigrants, free access to training (policy B) leads to $3.9 \%$ increase in annual earnings while no training (policy A) leads to $4.2 \%$ decrease in annual earnings. Hence, the gain of free access to training in comparison to no training is only $8.1 \%$ (compared to the $31.3 \%$ in Table 12). This implies that the main source for the large social gain we report above is through the effect of training on unemployment (Table 11), and not ,as conventionally thought, through its effect on wage.
} 
Although we do not have a direct method of calculating the difference in costs of the policies, we estimate that policy $\mathrm{C}$ is more expensive than free training (policy B) or the benchmark economy. Given the large social and private gain from training we can conclude that among the policies that we consider, the free training program (policy B) provides the highest social and private benefits. Given the esitmated numbers it is almost certain that also the net gain from policy B is substantial.

Table 11: The Effects of Each Policy Experiment on Labor Market Outcomes

\begin{tabular}{|c|c|c|c|c|c|}
\hline & $\begin{array}{c}\text { Benchmark* } \\
\text { (percent) }\end{array}$ & $\begin{array}{l}\text { Exp. A } \\
\text { (percent) }\end{array}$ & $\begin{array}{l}\text { Exp. B } \\
\text { (percent) }\end{array}$ & $\begin{array}{l}\text { Exp. C } \\
\text { (percent) }\end{array}$ & $\begin{array}{l}\text { Exp. D } \\
\text { (percent) }\end{array}$ \\
\hline At the 4th quarter & & & & & \\
\hline Employment in WC & 6.6 & 6.8 & 8.5 & 13.6 & 6.6 \\
\hline Employment in BC & 28.1 & 29.5 & 28.1 & 24.7 & 28.1 \\
\hline Training & 14.7 & 0.0 & 37.3 & 15.9 & 14.7 \\
\hline Unemployment & 50.6 & 63.8 & 26.1 & 45.8 & 50.6 \\
\hline At the 20th quarter & & & & & \\
\hline Employment in WC & 30.9 & 19.9 & 35.9 & 48.8 & 30.9 \\
\hline Employment in BC & 51.0 & 52.2 & 48.8 & 37.3 & 51.0 \\
\hline Training & 0.2 & 0.0 & 2.0 & 0.0 & 0.2 \\
\hline Unemployment & 17.9 & 27.9 & 13.3 & 13.9 & 17.9 \\
\hline $\begin{array}{l}\text { Accumulated no. of } \\
\text { trained immigrants }\end{array}$ & 249 & 0 & 401 & 270 & 249 \\
\hline
\end{tabular}

$\|{ }^{*}$ The benchmark refers to the simulated choices of the 502 female immigrants over 20 quarters at the ML estimation point. $\|$. 

Table 12: The Effects of Policy Interventions on Labor Market Outcomes on
Mean Accepted Wages*

\begin{tabular}{|c|c|c|c|c|c|c|c|c|c|c|}
\hline & & & \multicolumn{8}{|c|}{ Policy Experiment } \\
\hline & \multicolumn{2}{|c|}{ Benchmark } & \multicolumn{2}{|c|}{ Exp. A } & \multicolumn{2}{|c|}{ Exp. B } & \multicolumn{2}{|c|}{ Exp. C } & \multicolumn{2}{|c|}{ Exp. D } \\
\hline Time since & $\mathrm{WC}$ & $\mathrm{BC}$ & $\mathrm{WC}$ & $\mathrm{BC}$ & $\mathrm{WC}$ & $\mathrm{BC}$ & $\mathrm{WC}$ & $\mathrm{BC}$ & $\mathrm{WC}$ & $\mathrm{BC}$ \\
\hline \multicolumn{11}{|l|}{ arrival } \\
\hline 4th quarter & 14.30 & 9.29 & 15.32 & 9.34 & 16.94 & 9.49 & 15.26 & 9.45 & 20.3 & 9.30 \\
\hline 20 quarter & 25.03 & 10.09 & 23.31 & 10.23 & 28.35 & 10.14 & 26.42 & 9.84 & 25.03 & $\overline{10.09}$ \\
\hline \multicolumn{11}{|l|}{ By training } \\
\hline Before training & 19.51 & 9.88 & 19.25 & 9.84 & 19.95 & 9.81 & 19.80 & 9.90 & 20.46 & 9.88 \\
\hline After training & 23.19 & 9.66 & & & 23.29 & 9.73 & 22.80 & 10.19 & 23.56 & 9.66 \\
\hline $\begin{array}{l}\text { Annual Earnings } \\
\text { per Imm.** }\end{array}$ & \multicolumn{2}{|c|}{58,164} & \multicolumn{2}{|c|}{$47,576(-18)$} & \multicolumn{2}{|c|}{$65,800(13)$} & \multicolumn{2}{|c|}{$69,812(20)$} & \multicolumn{2}{|c|}{$58,164(0)$} \\
\hline $\begin{array}{l}\text { Expected Present } \\
\text { Value** (1995 NIS ) }\end{array}$ & \multicolumn{2}{|c|}{5033} & \multicolumn{2}{|c|}{$2951(-41)$} & \multicolumn{2}{|c|}{$7556(50)$} & \multicolumn{2}{|c|}{$6222(24)$} & \multicolumn{2}{|c|}{$5035(0)$} \\
\hline \multicolumn{11}{|c|}{${ }^{*}$ Wage per hour in July 1995 prices (NIS). } \\
\hline \multicolumn{11}{|c|}{ ** This is caclculated as average present value of accepted wages for the entire sample for 20 quarters. } \\
\hline In parenthesis is the & centage & ange re & tive to & he benc & mark. & & & & & \\
\hline
\end{tabular}

\section{Conclusions}

The dynamic choice model we adopt expands the literature on training in several dimensions: (i) It allows to motivate training not only as a conventional human capital investment decision, but also as a form of job search, as it affects the arrival rate of job offers; (ii) It allows training to affect also the non-participants as their labor supply decisions take into account the option to participate in training; (iii) Training evaluations tend to value labor supply in the non-market sector at a zero wage. Individuals, on the other hand, value their labor supply in the non-market sector as their reservation wage. The dynamic choice model evaluate training from the individual perspective; (iv) As indicated in Heckman, Smith and LaLonde (1999), most of the previous evaluations did not include employment history variables as explanatory variables in the participation decision. However, several studies suggest that previous labor force status of the individual and changes in this status affect participation in training. ${ }^{42}$ We study the simultaneous decisions to work and to

\footnotetext{
${ }^{42}$ For example, Card and Sullivan(1988) observed that trainee employment rates declined prior to entering training. Heckman and Smith(1999) found that unemployment is a powerful predictor of participation and that people who
} 
participate in CT. Hence, the decision to participate in training is affected by past activities the immigrant was engaged in and by current and expected future employment opportunities. Previous activity is, therefore, endogenous rather than exogenous in our model and; (v) While estimation of the return to various human capital stocks in a Mincerian wage regression treats the stocks as exogenous, estimation of the offered wage as a part of a dynamic choice model allows these stocks to be endogenously determined by the individual and affect her wage growth. The dynamic selectivity is, therefore, embedded in the model and the wage growth in this framework can be viewed as an outcome of the individual's choices.

The qualitative and quantitative results of this paper are similar to those obtained by CoehnGoldner and Eckstein (2002) for male immigrants. There we used a similar model and method of estimation, but a different exact specification. The similarity of the findings regarding the main sources and rates of return to training, indicate the robustness of the findings and their importance. The main message of these studeis is that training is highly valuable for all immigrants but is more valuable for older and less skilled workers since it provides them the option to leave unemployment for potentially better job. This result holds eventhough training has no impact on wages in bluecollar jobs and high rental value in while-collar jobs.

The study of the social and individual benefit from government provided training assumes that training affects the mean accepted wage through its affect on offered wage and employment probability. However, like investment in schooling, training may be a form of providing a signal by workers to employers. The possibility that part of the gains from training is in the form of a signal on the quality of the worker has not been studied and is a waiting empirical application.

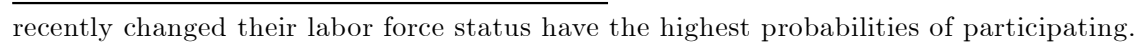




\section{References}

[1] Ashenfelter, O. (1978), "Estimating the Effect of Training Programs on Earnings", Review of Economics and Statistics, 6(1), 47-57.

[2] Baker,M.,and D. Benjamin (1997), "The Role of the Family in Immigrants' Labor Market Activity: An Evaluation of Alternative Explanations", American Economic Review, 87(4), 705-727.

[3] Bellman, R. (1957), Dynamic Programming, Princeton, New-Jersey, Princeton University Press.

[4] Card, D. and D. Sullivan (1988), "Measuring the Effects of CETA Participation on Movements In and Out of Employment, Econometrica, 56, 497-530.

[5] Card, D. (2001), "Estimating the Return to Schooling: Progress on Some Persistent Econometric Problems", Econometrica, 69, 1127-1160.

[6] Cohen, S. and Z. Eckstein (2002), "Labour Mobility of Immigrants: Training, Experience, Language and Opportunities", CEPR DP No. 3412.

[7] Duleep, H., Reget M. and S. Sanders (1999), "A New Look at the Human Capital Investment: A Study of Asian Immigrants and their Family Ties", Kalmazzo, MI: Upjohn Institute of Economic Research.

[8] Eckstein, Z. and Wolpin, K. I.(1989), "The Dynamics of Labour Force Participation of Married Women and Endogenous Work Experience", Review of Economic Studies,56, 375-390.

[9] Eckstein and K.I. Wolpin (1999), "Why Youth Drop Out of High School: The Impact of Preferences, Opportunities and Abilities, Econometrica, 67(6).

[10] Ham J.C. and R.J. LaLonde (1996), The Effect of Sample Selection and Initial Conditions in Duration Models: Evidence from Experimental Data on Training, Econometrica, 64(1), 175-207.

[11] Heckman, J.J., LaLonde, R.J. and J.A. Smith (1999), "The Economics and Econometrics of Active Labor Market Programs", in Handbook of Labor Economics, Vol. 3, A. Ashenfelter and D. Card (Ed.), North-Holland: Amsterdam. 
[12] Heckman, J. and B. Singer (1984), A Method for Minimizing the Impact of Distributional Assumptions in Econometric Models for Duration Data, Econometrica, 52(2), 271-320.

[13] Heckman, J. and J.A. Smith(1999), The Pre-Program Earnings Dip and the Determinants of Participation in a Social Program: Implications for Simple Program Evaluation Strategies, NBER Working Paper No. W6983.

[14] Hotz V. J. and, R.A. Miller(1988) An Empirical Analysis of Life Cycle Fertility and Female Labor Supply, Econometrica, 56(1), 91-118.

[15] Keane, M. P. and K. I. Wolpin (1994), "The solution and Estimation of Discrete Choice Dynamic Programming Models by Simulation and Interpolation: Monte Carlo Evidence", Review of Economics and Statistics, 76, 648-672

[16] Keane, M. P. and K. I. Wolpin (1997), "The Career Decision of Young Men", Journal of Political Economy, 105, 473-522.

[17] LaLonde R.J. (1995), "The Promise of Public Sector-Sponsored Training Programs", Journal of Economic Perspectives, 9.22, 149-168.

[18] Lucas, Robert E., Jr., (1976), "Econometric Policy Evaluation: A Critique.", In The Phillips Curve and Labor Markets, Edited by Karl Brunner and Allan H. Meltzer. Carnegie-Rochester Conference Series on Public Policy. Amsterdam: North-Holland.

[19] C. Manski, (1995), Identification Problems in the Social Sciences, Harvard University Press.

[20] Marschak, Jackob, (1953), "Economic Measurement for Policy and Predictions", In Studies in Economic Method, Edited by William C. Hood and Tjalling C. Koopmans, Coweles Monograph no. 14, New York: Wiley.

[21] McFadden, D. (1989), "A Method of Simulated Moments for Estimation of Discrete Response Models Without Numerical Integration", Econometrica, 57(5), 995-1026.

[22] Petra, Todd and Kenneth I. Wolpin (2003), " Using a Social Experiment to Validate a Dynamic Behavioral Model of Child Schooling and Fertility: Assessing the Impact of a School Subsidy Program in Mexico", http://athena.sas.upenn.edu/ petra/papers/revpaper.pdf. 
[23] Van Der Klaauw W.(1996), "Female Labour Supply and Marital Status Decisions: A life-Cycle Model", Review of Economic Studies, 63,199-235.

[24] Weiss, Y. and R. Gronau (1981), "Expected Interruptions in Labour Force Participation and Sex-Related Differences in Earnings Growth", Review of Economic Studies, 48(4), 607-619. 


\subsection{Appendix}

Table A1: Estimated parameters

\begin{tabular}{|c|c|}
\hline $\begin{array}{l}\text { Training Offer Probabilities } \\
p t_{1} \text { (if age at arrival }<40 \text { ) }\end{array}$ & 0.1361 \\
\hline$p t_{2}$ (if age at arrival $\left.\geqslant 40\right)$ & 0.0575 \\
\hline $\begin{array}{l}\text { Terminal Value estimates } \\
\delta_{1} \text { - accumulated experience in WC }\end{array}$ & 633.335 \\
\hline$\delta_{2^{-}}$accumulated experience in $\mathrm{BC}$ & $\begin{array}{r}520.462 \\
(3.140)\end{array}$ \\
\hline$\delta_{3^{-}}$age at arrival & $\begin{array}{r}-65.138 \\
(3.152)\end{array}$ \\
\hline$\delta_{4^{-}}$training & $\begin{array}{c}1399.968 \\
(3.162)\end{array}$ \\
\hline$\delta_{5^{-}}$constant & $\begin{array}{l}1426.678 \\
(3.162)\end{array}$ \\
\hline$\delta_{6}$ - worked in WC during the last period & $\begin{array}{l}379.179 \\
(3.163)\end{array}$ \\
\hline$\delta_{7^{-}}$worked in $\mathrm{BC}$ during the last period & $\begin{array}{l}-0.093 \\
(3.154)\end{array}$ \\
\hline$\delta_{8}-$ years of schooling & $\underset{(3.132)}{150.200}$ \\
\hline$\delta_{9^{-}}$Number of children & $\underset{(3.162)}{100.064}$ \\
\hline$\delta_{10^{-}}$married & $\begin{array}{l}99.979 \\
(3.162)\end{array}$ \\
\hline$\delta_{11^{-}}$worked in WC in USSR & $\begin{array}{r}99.363 \\
(3.164)\end{array}$ \\
\hline$\delta_{12^{-}}$Hebrew & $\begin{array}{r}35.988 \\
(3.162)\end{array}$ \\
\hline $\begin{array}{l}\text { Utility Estimates } \\
\text { constant-employment } \\
\text { children-employment }\end{array}$ & $-\underset{(0.0898)}{29.512}$ \\
\hline marriage-employment & $\begin{array}{r}124.960 \\
(3.1551)\end{array}$ \\
\hline constant-training & $\begin{array}{r}-15.955 \\
(3.1610)\end{array}$ \\
\hline children-training & -2.762 \\
\hline marriage-training & $\begin{array}{r}-12.620 \\
(3.1591)\end{array}$ \\
\hline constant-unemployment & -591.648 \\
\hline children-unemployment & $\begin{array}{l}-1.361 \\
(3.1594)\end{array}$ \\
\hline marriage-unemployment & $\begin{array}{l}40.462 \\
(3.1613)\end{array}$ \\
\hline
\end{tabular}




\begin{tabular}{l|r} 
Cholesky Decomposition estimates & \\
$\sigma_{11}$ & 0.286 \\
$\sigma_{22}$ & 0.150 \\
$\sigma_{33}$ & 0.051 \\
$\sigma_{44}$ & 9.883 \\
Cov $_{34}$ & -0.476
\end{tabular}

* standard errors in parenthesis 
Figure 1: Actual Choice Distribution

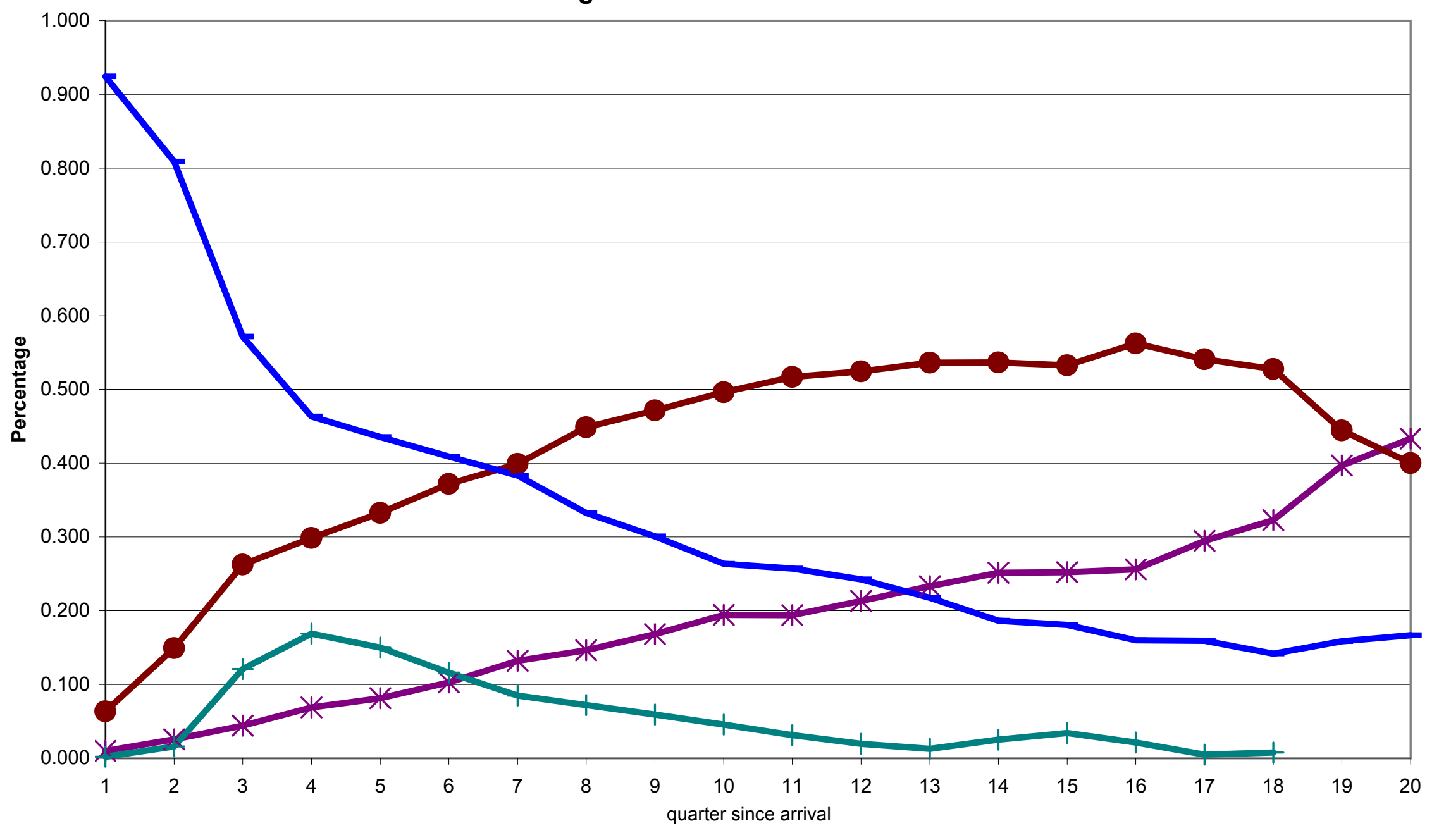

$\because$ occ1-Actual $\longrightarrow$ occ2-Actual + training-Actual $\longrightarrow$ unemploy-Actual 
Figure 2: Actual Hazard to Training

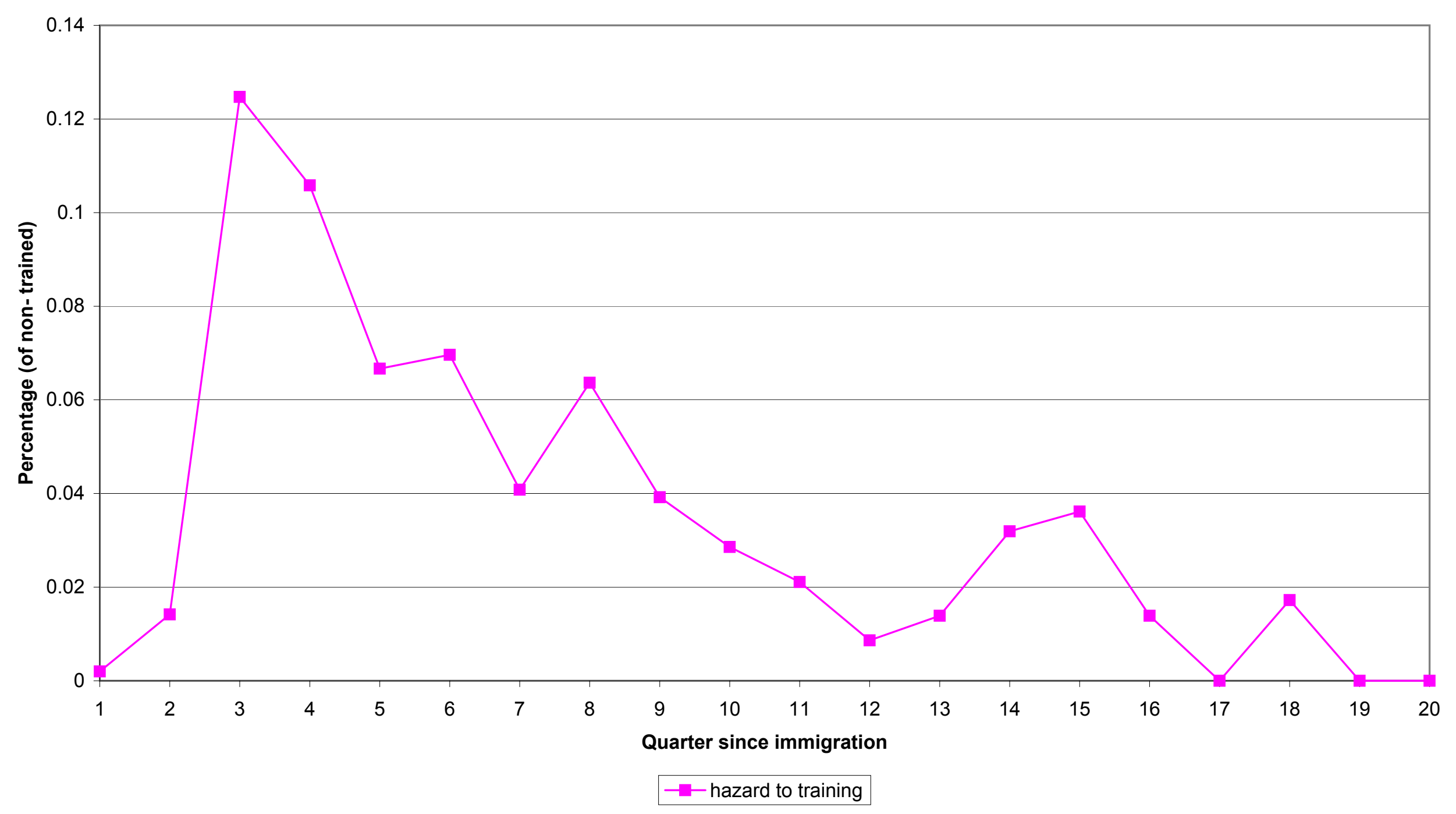

